\title{
LA BIOÉTICA Y EL BIODERECHO EN EL ORDENAMIENTO JU RÍDICO CUBANO
}

\author{
Alcides Antúnez Sánchez ${ }^{1}$ \\ Leaned Matos Hidalgo ${ }^{2}$ \\ Manuel Felipe Ledea ${ }^{3}$
}

\section{Resumen}

La asignatura Bioética y Derecho Civil perteneciente a la Disciplina Derecho Civil y Familia, se encuentra incorporada al currículo optativo de la Carrera de Derecho de la Universidad de Granma, desde la implementación del Plan de Estudios D, la misma se encarga de acercar a los estudiantes al análisis de la relación bioética y bioderecho, el carácter de la vida ante el Derecho, entre otros elementos que refuerzan la formación humanista del sistema educativo, así como del profesional del Derecho, aspectos que ante el proceso de actualización del ordenamiento jurídico cubano, necesita de una reevaluación de los contenid os y el material bibliográfico utilizado.

Palabras llaves: Bioética y Derecho Civil. Bioderecho. actualización del ordenamiento jurídico.

\footnotetext{
${ }^{1}$ Máster en Asesoría Jurídica mención a mbiental. Profesor Auxiliar Derecho Ambientale Internacional Público en la Disciplina de Empresas. Facultad de Ciencias Económicas y Sociales. Universidad de Granma. República de Cuba. Email: a antunez@udg.co.cu Orcid Id: http://orcid.org/0000-0002-8561-6837

${ }^{2}$ Licenciada en Derecho. Profesora Asistente Derecho Penal y Teoría en la Disciplina Penal. Facultad de Ciencias Económicas y Sociales. Universidad de Granma. República de Cuba. Email: 1ma tosh@udg.co.cu Orcid Id: http://orcid.org/0000-0002-4182-1732

${ }^{3}$ Dr. en Medicina. Especialista de $2{ }^{\text {do }}$ Gradoen Medicina Legal. Profesor Auxiliar Medicina Le gal. Prof esor Principal Universidad de Ciencias Médicas. Profesor Auxiliar de la Disciplina Penal. Facultad de Ciencias Económicas y Socia les. Universidad de Granma. República de Cuba. Email: mfelipe@ infomed.sld.cu Orcid Id: $\underline{\text { http://orcid.org/0000000100016816 }}$
} 


\title{
The bioethics and the bioright in the juridical organizing Cuban
}

\begin{abstract}
Abstrac
The subject of study Bioetic and Civil Law into discipline Civil Law and Family, you meet once the optative curriculum of Derecho's Race of Granma's University, from the implementation of the Curriculum was incorporated to D, the same takes charge of the humanist of the educational system brings near bioetic and biolaw, the symbol of the life in front of the right, between another elements that reinforce the formation to the students to the analysis of the relation, that way I eat of the professional of the right, aspects than in front of the process of bringing up to date of the juridical organizing Cuban, he is in need of a re-evaluation of the contentses and the bibliographic utilized.
\end{abstract}

Keywords: Bioetic and Civil Law. Biolaw. bringing up to date of the juridical organizing.

Material y métodos: El artículo, tiene como objetivo demostrar la necesidad de actualizar los contenidos de la asignatura Bioética y Derecho Civil desde la disciplina Derecho Civil y Familia del Plan de Estudios E de la carrera de Derecho en la Universidad de Granma a partir del curso 2020-2021 con la actualización del ordenamiento jurídico, lo que permitirá entregar un profesional con competencias incidente en su modo de actuación como profesional del Derecho. Para ello, fueron utilizados como métodos: la revisión bibliográfica, el análisis histórico, deducción inducción, y el de comparación jurídica. 


\section{Introducción}

En los últimos años la humanidad ha sido testigos de una notable dinámica social, la que ha ocasionado que haya venido cambiando de manera vertiginosa la relación del hombre con el ambiente. Los avances científicos y tecnológicos logrados han dado como resultado que la sociedad sea cada día más libre, plural, informada, autónoma, participativa y consciente de su s derechos. Por ello, es de relevancia señalar que históricamente se habla de cuatro generaciones de derechos humanos: primero los derechos civiles y políticos durante la segunda mitad del siglo XIX; posteriormente los derechos económicos, sociales y culturales en la primera mitad del siglo XX; después, los derechos ecológicos y a un medio ambiente sano en la segunda mitad del siglo XX; y ahora se habla de una última generación de derechos relacionados con los avances científicos y tecnológicos en el siglo XXI. ${ }^{4}$

En efecto el tema de la bioética, es considerada en el ámbito académico como una disciplina, su origen se debe al neologismo creado por POTTER, quien entre sus profesiones como bioquímico, oncólogo e investigador en Norteamérica, tiene el mérito científico de acuñar el término bioética (bios: vida y ethos: ética), con el fin de mostrar la necesidad de reorientar la filosofía práctica de la vida, y para profundizar en su significado. ${ }^{5}$

Por supuesto, esta disciplina expresa la maduración del pensamiento contemporáneo propiciado por el auge que adquirió el desarrollo alcanzado de estas ramas en las décadas del 60' y el 70' del pasado siglo, y los impactos negativos en las sociedades industrializadas al ambiente. Su estudio muestra una creciente aceptación académica y social en la actualidad, pues la visión biomédica que inicialmente le estampó a la disciplina propuesta por el Kennedy Institute of Ethics de la Universidad de Georgetown en Washington, por ello, la idea originaria de POTTER cobra fuerza y se percibe a la bioética como una materia que promueve la integración de los valores, el conocimiento y la práctica. En América Latina este nuevo saber irrumpe en los círculos académicos, con pertinencia en el sector biomédico, y en su de sarrollo irrumpe en la formación jurídica en la carrera de Derecho como legado para las generaciones futuras para formar un profesional con competencias.

\section{Un breve estudio del marco jurídico internacional en la Bioética y el Bioderecho desde el Derecho Internacional}

Los fundamentos filosófico jurídicos de la Declaración Universal de los Derechos Humanos desde el Derecho Internacional, se valora que expresa con rigor y profundidad las cuestiones fundamentales acerca de los derechos del hombre y así mismo, enuncia con claridad

${ }^{4}$ O.N.U. (1948) Declaración Universal de los Derechos Humanos. Adoptada y proclamada por la Asa mblea Generalen su resolución 217 A(III).

${ }^{5}$ Potter, V. (1971) Bioethics Bridge to the Future. Editorial Prentice-Hall, E.U.A. pp.1-2.

Rev. Campo Juridico, barreiras-BA v.8 n.2, p. 140-174, Julio-Diciembre, 2020. 
que se trata de derechos inherentes al ser humano desde el ámbito in ternacional. Este hecho histórico jurídico acontecido en Paris en el año 1948, ocurre después de largas ne gociaciones entre los países que entonces formaban la Organización de las Naciones Unidas en este momento analizado. ${ }^{6}$

Por esta razón se valora que, la Declaración de los Derechos Humanos constituye la corriente clásica y realista del iusnaturalismo. Por ello, paradójicamente el siglo XX fue el siglo que ha visto gestar la Declaración Universal de los Derechos del Hombre. El recorrido del siglo $\mathrm{XX}$, ha resultado un tiempo que ha presenciado, como pocos momentos de la historia humana, atentar dramática y cruelmente contra la vida y la dignidad del hombre. ${ }^{7}$

Para una mejor comprensión será analizada los aportes teóricos, en tre e stos el artículo "Utilitarismo y derechos naturales" de HART al afirmar “...Es claro que se necesita urgentemente una teoría de los derechos. Durante la última mitad de siglo la inhumanidad del hombre para con el hombre ha sido tal que las más básicas y elementales libertades y protecciones les han sido denegadas a innumerables hombres y mujeres, culpables tan solo por haber exigido esas libertades y protecciones para símismos y para otros, resultando que en ocasiones éstas se les han negado con la pretensión espuria de que tal denegación era demandada por el bienestar general de una sociedad. De esta manera, la defensa de una doctrina de los derechos humanos básicos que limite lo que un estado puede hacer con sus ciudadanos parece ser lo que más urgentemente requieren los problemas políticos de nuestro tiempo..."

La opinión del profesor GARCÍA MÁYNEZ al ilustrar la diversidad de visiones que existen al acercarse al iusnaturalismo: La circunstancia de que haya tantas teorías acerca del derecho natural suscita de inmediato un problema: ¿puede hablarse del iusnaturalismo como de una posición teórica unitaria, en el sentido en que hablamos de la postura antitética? Mi opinión es que, si bien no hay una, sino múltiples, casi siempre discrepantes, concepciones en torno de lo que se denomina -con término muy ambiguo- derecho natural, debemos, no obstante, preguntarnos por el elemento que, pese a tales discrepancias, permite englobar las mencionadas corrientes bajo un solo rubro y contraponerlas al positivismo jurídico. ${ }^{9}$

Por esta razón se arguye que unir los saberes de la Bioética y el Derecho es pertinente, no para juridificar a la primera, sino para entender los valores constitucionales y los principios generales de las naciones civilizadas como acuerdo mínimo de la Declaración de Derechos

${ }^{6}$ O.N.U. (1948) Decla ración Universal de los Derechos Humanos. Adoptada y proclamada por la Asa mblea Generalen su resolución 217 A(III).

${ }^{7}$ O.N.U. (1948) Decla ración Universal de los Derechos Humanos. Adoptada y proclamada por la Asa mblea Generalen su resolución 217 A(III).

${ }^{8}$ Hart, H. (2003) Utilitarismo y derechos naturales. Editorial UniversidadExtern ado de Colombia. B ogotá; Hart, H. (2004) El concepto de Derecho. Editorial Abeledo Perrot, Argentina.

${ }^{9}$ García Máynez, E. (1999) Positivismojurídico, realismo sociológico y iusna turalismo. Biblioteca de ética, filosofía del derechoy política. México.

Rev. Campo Juridico, barreiras-BA v.8 n.2, p. 140-174, Julio-Diciembre, 2020. 
Humanos y de las demás declaraciones internacionales y convenios que forman parte del acervo común, de aquí su reconocimiento en los textos constitucionales. De modo que, se pondera que los Derechos Humanos constituyen a la vez la base jurídica y el mínimo ético irrenunciable sobre los cuales se asientan las sociedades democráticas desde el Derecho Internacional. De esta manera se han irradiado a los textos constitucionales de las naciones que lo h an con cebido en sus ordenamientos jurídicos, hoy con el uso de las Tecnologías de la Informática y las Comunicaciones (TIC) a mayor velocidad. ${ }^{10}$

En este estudio, se aprecia como JAHR, llamado el "Padre de la Bioética", utiliza por primera vez la palabra en el año 1927, este suceso quedó sentado en editorial de la revista alemana de ciencias naturales Kosmos. ${ }^{11}$ Después en otras publicaciones este autor estudiado, mencionó un "imperativo bioético" que representaba el imperativo categó rico de l le gado de KANT. $^{12}$

La historia sigue develando que, a raíz de los grandes avances tecnológicos en el áre a de las ciencias de la salud, en la década de los 70' del pasado siglo, surgió una nueva disciplin a en la que convergieron tres ciencias principalmente integrando contenidos des de la Filosofía, la Medicina y el Derecho. El nacimiento a esta nueva disciplina se le llamó Bioética. ${ }^{13}$

Para el desarrollo de este artículo, se constata como otros autores le atribuyen el mérito científico al bioquímico estadounidense POTTER, sobre la paternidad del término "Bioética", el autor estudiado lo utilizó por primera vez en su artículo "Bioética: La ciencia de la supervivencia", publicado en 1970 y luego lo confirma en su libro: "Bioética: Puente hacia el futuro", publicado en 1971. Se señala que este autor estudiado fue quien acuñó la palabra uniendo los vocablos griegos bios, que significa vida, y ethos, que significa comportamiento o costumbre. Etimológicamente se trata de la "ética de la vida". ${ }^{14}$

Este autor estudiado, en su obra "Bioethics Bridge to the Future", definió la Bioética como una disciplina de encuentro de saberes para alcanzar una nueva cultura de la supervivencia: La humanidad está urgentemente necesitada de un nuevo saber que proveerá el conocimiento de cómo usar el conocimiento, para la supervivencia del hombre y para el mejoramiento de la calidad de vida... Una ciencia de la supervivencia debe ser más que una ciencia particular, y por lo tanto propongo el término bioética para recalcar sus dos más

\footnotetext{
${ }^{10}$ Véa se, Bobbio, N. (1993) Elfuturo de la democracia. EditorialFondocultura Ec onómica. México; Pérez Luño, A. (2013) Las generaciones de derechos humanos. Revista Direitos Emergentes na Socie dade Global, No. 1: Ferrajoli, L. (2010) Democracia y ga ra ntismo. Editorial Trotta. Espña.

${ }^{11}$ Jahr, F. (1927) BioEthik: Eine Umschau über die ethischen Beziehungen des Menschen zu Tier und Pfla nze. Kosmos: Handweiser für Naturfreunde No 24,pp. 2-4.

${ }^{12}$ Kant, I. (1968) Kritik der reinen Vernunft. Bände. Darmstadt: Wissenschaftliche Buchgessellschaft, pp.4-5

${ }^{13}$ Abel I Fabre, F. (2001) Bioética: Orígenes, presente y futuro, Editorial Mapfre, España.

${ }^{14}$ Potter, V. (1971) Bioethics: Bridge to the future. Edition Prentice-Hall, EUA. 
importantes ingredientes para alcanzar ese nuevo saber que se requiere con urgencia: conocimiento biológico y valores humanos. ${ }^{15}$

El autor estudiado refiere en sus apuntes que la Bioética en sus inicios surge como un intento de establecer un "puente" entre el saber científico y el saber humanístico-moral, este puente se establece entonces como el único camino de solución posible ante el proceso científico y tecnológico indiscriminado que pone en peligro la humanidad y su propia supervivencia. En este contexto, la ética no sólo debe referirse al ser humano, sino que se debe extender a la vida en general. La aplicación de cualquier conocimiento científico puede tener consecuencias irremediables para la humanidad al concentrar la biotecnología en poder de unos pocos. ${ }^{16}$

Esto nos lleva a revisar como en los Estados Unidos de América, la labor del movimiento bioético tiene su inicio en la década del 70', fue un fenómeno sociocultural caracterizado por un bios tecnológico, un ethos secular. Se distinguió por la tecnificación de la vida y la liberalización de la moral sustentada en la racionalidad humana. De lo anterior resulta que, en el año 1978, se definiera por primera vez el término Bioética como "El estudio sistemático de la conducta humana en el campo de la ciencia de la vida y la salud, analizada a la luz de los valores y principios morales" 17

Al consultar en el desarrollo del artículo al Diccionario de la Lengua española, se aprecia cómo este define a la Bioética: "disciplina científica que estudia los aspectos éticos de la medicina y la biología en general, así como las relaciones del hombre con los restantes seres vivos". ${ }^{18}$

Así pues, en su avance en el año 1988, nace una nueva etapa de la Bioética lla mada por POTTER como "Bioética Global". En esta etapa se sistematizan las ideas referentes a la construcción de un nuevo puente que una a la ética médica y la ética medioambiental considerando al bienestar humano en el entorno del respeto por el medio ambiente y la naturaleza. ${ }^{19}$

Otros autores estudiados para conformar el artículo, como RoY, expresa su concep to, y señala “...La Bioética es el estudio interdisciplinar del conjunto de condiciones que exige una gestión responsable de la vida humana en el marco de los rápidos y complejos progresos del saber y de las tecnologías biológicas..."20

\footnotetext{
${ }^{15}$ Potter, V. (1971) Bioethics: Bridge to the future. Edition Prentice-Hall, EUA.

${ }^{16}$ Vgr. Potter, V. (1971) Bioethics: Bridge to the future.

${ }^{17}$ Bola deras Cucurella, M. (1999) Bioética, Editorial Síntesis, España.

${ }^{18}$ Diccionario de la Lengua Española (2014) $23{ }^{\text {ra }}$ edición, Real Aca demia Española y Asocia ción de Aca demias de la Lengua Española, EditorialEspasa, España.

${ }^{19}$ Vgr. Potter, V. (1971) Bioethics: Bridge to the future.

${ }^{20}$ Roy, D. (1979) La biomédicine aujourd'hui et l'homme de demain. Point de départ et direition de la bioétique. Le Suplément, No 28, pp.59-75
}

Rev. Campo Juridico, barreiras-BA v.8 n.2, p. 140-174, Julio-Diciembre, 2020. 
REICH, puntualiza desde su posición que la Bioética es “...El estudio sistemático de la conducta humana en el campo de las ciencias de la vida y de los cuidados de la salud, en la medida en que esta conducta se examine a la luz de los valores y principios morales..."21

Por consiguiente, la definición de Bioética desde la postura de REICH en la Encyclopedia of Bioethics, durante décadas se constata como resultó ser la más divulgada y aceptada: Estudio sistemático de la conducta humana en el área de las ciencias de la vida y la atención de salud, en tanto dicha conducta es examinada a la luz de los principios y valores morales... La Bioética abarca la ética médica, pero no se limita a ella. La ética médica en su sentido tradicional, trata de los problemas relacionados con los valores que surgen de la relación entre médico y paciente. 22

Por ello, se puede aseverar que el progreso que ha tenido la medicina y la biología han ocasionado dilemas éticos para el hombre y para los especialistas, sean estos médicos, biólogos, científicos, filósofos o juristas. La primera toma de conciencia colectiva de los problemas éticos de la medicina por el hombre, datan de la Segunda Guerra Mundial con las revelaciones de los experimentos médicos realizados por el nazismo. El Código de Nuremberg de 1947, constituye el primer conjunto de normas internacionales que relacionan la ética médica y los derechos humanos. Las Declaraciones de la Asociación Medica Mundial en Helsinki (1964) en Tokio (1975) y en Manila (1980), se corrobora como incidieron en el principio fundamental de que hombres y mujeres no pueden ser un simple objeto para la ciencia. ${ }^{23}$

De aquí que, la Declaración Universal de los Derechos Humanos de la ONU de 1948, haya sido un gran paso en la historia de la humanidad. Desde el Derecho Internacional, es fru to directo de la gran preocupación que dejó la Segunda Guerra mundial y los horrorosos abusos cometidos por los nazis. ${ }^{24}$ También, en la conferencia de Asilomar se ilustran las preocupaciones de la comunidad científica ante la posibilidad de manipu lar la molécula que contiene información genética o ADN -fue el descubrimiento que impulso a la biología molecular- produjo inquietud ante los posibles riesgos derivados de la transferencia de genes. ${ }^{25}$

\footnotetext{
${ }^{21}$ Reich, W. (1978) Encyclopedia of bioethics. Editorial Free Press, EUA.

${ }^{22}$ Warren, T. (1978) Introduction. Encyclopedia of Bioethics. Editorial Free Press-Macmillan. New York, pp. 16-19.

${ }^{23}$ En 1997, elCódigo de Nüremberg fue publicadoel 20 de a gosto de 1947, producto del Juicio de Nüre m berg (agosto 1945 a octubre 1946), en elque, junto con la jerarquía nazi, resultaron condenados varios médicos por gra vísimos atropellos a los derechos humanos. Dicho tex to tiene el mérito de ser el prim er docum en to que planteó explícitamente la obliga ción de solicitar elConsentimiento Informado, ex presión de la auto nomía del paciente Adoptada por la 18 Asa mblea Médica Mundial, Helsinki, Finlandia, junio de 1964 y enmendada por la 29 Asa mblea Médica Mundial, Tokio, Japón, octubre de 1975, la 35 Asamblea Médica Mundial, Ven ecia, Ita lia, octubre de 1983 y la 41 Asa mblea Médica Mundial, Hong Kong, septiembre de 1989.

${ }^{24}$ O.N.U. (1948) Declaración Universal de los Derechos Humanos. Adoptada y proclamada por la Asa mblea Generalen su resolución 217 A(III).

${ }^{25}$ En 1975 se convocó una Conferencia internacional de Asilomar para tratar las implicaciones de la s nuevas tecnologías entonces disponibles para modificar el genoma de orga nismos mediante la inserción o eliminación de segmentos de ADN.
} 
Por lo tanto, en este contexto analizado surge la Bioética como la disciplina que, desde un enfoque plural, pone en relación el conocimiento del mundo biológico con la formación de actitudes y políticas encaminadas a conseguir el bien social. En la continuidad, la década de los 90', se da paso al surgimiento de la etapa denominada "Bioética Profunda", donde se exploran los nexos que existen entre los genes y la conducta ética, ya que con el capitalismo los puentes entre los conocimientos empíricos de las ciencias naturales y sociales ya no eran suficientes para garantizar la supervivencia. ${ }^{26}$ Por ende, se asevera que la bioética es una disciplina interdisciplinar.

Así, para reflexionar sobre la Bioética resulta importante el proceso de elaboración y el análisis de las normas que deben regir la acción en lo que se refiere a la intervención técnica del hombre sobre su propia vida. Las normas jurídicas poseen una evidente relación con las morales, aunque no dependan de la ética para su configuración, y a lo largo de los siglos el análisis de estas relaciones ha sido una cuestión central del pensamiento filosófico-jurídico.

Desde la ciencia del Derecho, se aprecia el aporte legado por el catedrático MARTín MATEO, uno de los primeros juristas que abordó en España el tema de la relación entre Bioética y Derecho al señalar: “...Es, pues, necesario que el legislador intervenga ordenando conducta s y puntualizando extremos no deducibles sin más de las vagas formulaciones de la bioética, lo que no puede quedar al libre arbitrio e interpretación de profesionales e investigadores". Antes ya había sostenido este autor, frente al antiguo enfoque ético de la práctica médica, que "la tenaz defensa de la ética tradicional que ciertos profesionales de la medicina realizan, olvida en primer lugar que, como enseña la historia, no hay valores inmutables, y por otra parte, y esto es lo definitivo, que una cosa es la moral subjetiva y otra la comunitaria, por lo que no pueden imponerse a otros sacrificios y trastornos invocando dogmas no compartidos ..."27

Vinculado al tema, también DíEZ-PICAZO, desde su postura como civilista, refiere “...el bien jurídico protegido por el derecho a la vida es el carácter valioso de la vida humana o la convicción de que toda vida humana es digna de ser vivida. El derecho a la vida, según el autor consultado, constituye el soporte físico de todos los demás derechos fundamentales..."28

Para el profesor ATIENZA, quien valora sobre el derecho a la vida, la cual la traduce en los siguientes argumentos sobre el tema del artículo: 1) El Estado de ninguna manera puede efectuar medidas en contra de la voluntad del titular del derecho a la vida, a efecto de mantenerlo con vida. 2) El derecho a la vida implica que se tiene derecho a vivir o a morir y que los demás, y, en su caso, el Estado no solo tiene deberes negativos, sino también pos itivos de garantizarnos la vida. 3) El derecho a la vida solo puede limitarse si su ejercicio afecta derechos

\footnotetext{
${ }^{26}$ Potter, V. R. (1998) Bioética puente, bioética global y bioética profunda. Cuadernos del Programa Regional de Bioética, 7. Organiza ción Panamericana de la Salud y Orga nización Mundialde la Salud.

${ }^{27}$ Martín Mateo, M. (1997) Bioética y Derecho, Editorial Ariel, Barcelona.

${ }^{28}$ Díez-Picazo, L. (2008) Sistema de derechos fundamentales. $3{ }^{\text {ra }}$ Edición, Editorial Thomson Civitas, España.
} Rev. Campo Juridico, barreiras-BA v.8 n.2, p. 140-174, Julio-Diciembre, 2020. 
fundamentales de terceros o supusiera un riesgo para el sistema democrático, entre otros riegos igualmente graves. ${ }^{29}$

GARRAFA, desde la Cátedra UNESCO de Bioética, para quien el trasfondo de la vida no le resulta determinante en su tesis, como en los casos previos refiere que "La Bioética es más que la ciencia de la supervivencia, es una herramienta concreta que contribuye en el proceso complejo de discusión y aplicación de problemas". ${ }^{30}$

En contexto, se analiza, además, como los instrumentos jurídicos a partir de la resolución emitida por la Asamblea General de la ONU el 2008, sobre la Declaración Universal de los Derechos Humanos, se afirmó que esta "desde que se aprobó, ha inspirado al mundo y ha empoderado a mujeres y hombres de todo el planeta para hacer valer su dignidad inherente y sus derechos sin discriminación por motivo alguno". En la actualidad se habla de derechos humanos de cuarta generación, estos nacen a finales del siglo XX, e inicios del presente siglo XXI, se refieren a los avances científicos y tecnológicos, que son en buena medida los derechos no escritos de la mayoría de los sistemas jurídicos occidentales, siendo pionera la Carta de Derechos Fundamentales de la Unión Europea. Estos derechos humanos son los relacionados con la identidad genética, integridad genética, intimidad genética, el consentimiento informado en la intervenciones relacionadas con la salud, la protección de datos personales, el acceso universal a las nuevas tecnologías, la intimidad informática y el derecho a que se fomente el flujo e intercambio de comunicación. ${ }^{31}$

Conlleva a justipreciar en este análisis como el Derecho y la Bioética se han unido para dar pie a una nueva disciplina jurídica que sistematiza y da coherencia jurídico-ética a las nuevas realidades que emergen del ámbito de la conducta humana conocida como Bioderecho. ${ }^{32}$ También, se aprecia en su desarrollo como organismos intemacionales han aprobado textos como: el Convenio sobre Diversidad Biológica de Río de Janeiro, auspiciado por las Naciones Unidas, o la Declaración de los Derechos de las Generaciones Futuras y la Declaración Universal sobre el Genoma Humano de la UNESCO, son instrumentos jurídicos que desde el Derecho Internacional pretenden completar la Declaración Universal de Derechos Humanos. ${ }^{33}$

Consecuentemente, se pondera que el Derecho debe estar atento a los cambios científico s tratando de controlar los riesgos potenciales de los mismos, sin ser un obstáculo a la innovación, sino actuando como elemento de racionalización y de garantía. Sin perder de vista la necesidad de que sus normas están dotadas de la temporalidad limitada que requiere una materia en

\footnotetext{
${ }^{29}$ Atienza, M. (2003) Tras la justicia. Editorial Ariel Derecho, España, pp. 114 y ss.

${ }^{30}$ Garrafa, V. (2013) Diez a ños de la Redbioética. Logros y desafíos en la bioética latin oamericana. Revista Redbioética/UNESCO, No 2,pp.17-27.

${ }^{31}$ O.N.U. (1948) Decla ración Universal de los Derechos Humanos. Adoptada y proclamada por la Asa mblea Generalen su resolución 217 A(III).

${ }^{32}$ Ca sa do González, M. (1998) Bioética, Derecho y sociedad. EditorialTrotta. España.

${ }^{33}$ O.N.U. (1948) Declaración Universal de los Derechos Humanos. Adoptada y proclamada por la Asa mblea Generalen su resolución 217 A(III).
} 
continua evolución y basadas en el consenso que, idealmente, debe seguir al debate social informado que tanto se preconiza.

Por ello, se justiprecia que la Bioética es una categoría-concepto, que tiene diferentes interpretaciones; posee una doble perspectiva, porque contempla una parte clínica o terapéutica que tiene que ver con el curar y el cuidar, y por otro lado, una práctica relacionada con el ejercicio bioético. Es un esfuerzo para legitimar los saberes prudenciales en la experiencia, les concierne a todos los individuos; por esta razón, es necesario darla a conocer y ponerla en práctica, para tener hábitos que anulen todo lo que vaya en contra de la existencia, porque en la bioética, el asunto es de una actitud positiva con el propósito de apoyar la vida.

Entonces, se puede aseverar que la Bioética lucha en favor del respeto por los derec hos humanos, de los animales y del ambiente; propugna por la prevalencia del individuo frente al interés exclusivo de la sociedad o de la ciencia, es transdisciplinaria, global y flexible, se convierte en una excelente oportunidad para que cambie el modo de actuar con el objetivo de potenciar la vida sobre el planeta. En este íter analizado, se aprecia que, desde los pueblos originarios de América del Sur, con una nuevo Derecho Ambiental, aportan la noción de buen vivir o vida buena, es uno de los aspectos estratégicos de la ecología profunda. Ese mand ato ético ancestral, retomado por la Ecología profunda, requiere superar la imaginería del merc ado impuesto por la cultura hegemónica desde las naciones industrializadas. Sin embargo, mien tras que la Bioética en el contex to de las culturas orientales ha tratado de ser recreada desde sus respectivas tradiciones ético-filosóficas. Empero, hay que significar que la Bioética en Latinoamérica tiene una deuda pendiente con las culturas originarias. ${ }^{34}$

En este estudio, se pondera como la UNESCO ha venido desarrollando una activa presencia internacional en temas de la Bioética. La Declaración Universal de Bioética y Derechos Humanos, se aprecia que resultó en una victoria política y moral del Sur. Su fundamento trasciende los modelos psicologistas anglosajones, así como al modelo personalista europeo, para proponer un sistema de principios mucho más amplio e inclusivo: dignidad humana y derechos humanos; beneficios y efectos nocivos; autonomía y responsabilidad individual; consentimiento; personas carentes de la capacidad para dar su consentimiento; respeto a la vulnerabilidad humana y la integridad personal; privacidad y confidencialidad, igualdad, justicia y equidad; no discriminación y no estigmatización; respeto a la div ersidad cultural y del pluralismo; solidaridad y cooperación; responsabilidad social y salud; aprovechamiento compartido de los beneficios; protección de las generaciones futuras; protección del medio ambiente, la biosfera y la biodiversidad. ${ }^{35}$

\footnotetext{
${ }^{34}$ Antúnez Sánchez, A. (2019) La bioética en el pensamiento del legisla dor ecuatoriano en la protec ción de la Pacha Mama. Revista Derecho \& Paz No. 40. Brasil.

${ }^{35}$ Oficina Regional de Ciencia de la UNESCO para América Latina y elCaribe (2008) Progra ma de base de estudios bioéticos. Montevideop.18
}

Rev. Campo Juridico, barreiras-BA v.8 n.2, p. 140-174, Julio-Diciembre, 2020. 
En su evolución y desarrollo en el siglo XXI, se constata que con el rápido progreso de la tecnología en las ciencias de la salud ha originado su necesidad de regularla. Esta tecnología ha introducido en la sociedad una especie de "medicalización de la vida" y la "juridicidad de la sociedad", ligando de esta manera a la Bioética y el Derecho en una especie de simbiosis o unión disciplinaria debido a su transdisciplinariedad. También, se debe señalar que es a partir del 2000, surgen las bioéticas latinoamericanas y africanas, que hablan de pobreza, in equidad, catástrofes en general, como el cambio climático, terremotos, huracanes, tornados, etc., y reflexionan sobre los efectos en los territorios.

\subsection{Los aportes desde la Filosofía a la Bioética}

La vida de los organismos de superioridad ética ha sido protegida jurídic amente en su vertiente objetiva desde cientos de años antes de Cristo, pu ede citarse como ejemplos al Código de Hammurabi (1728 a.C.) y las leyes de la cultura maya en Mesoamérica (400 a.C.), en las que se castigaba a todo el que privaba de la vida a otro. ${ }^{36}$ Pasarían muchos años para que se declarara en forma expresa el derecho a la vida, se considera que se dio en 1776 con la Declaración de Derechos del Buen Pueblo de Virginia y la Declaración de Independencia de Estados Unidos; fueron fuentes de inspiración y precedentes importantes para la Declaración Universal de los Derechos del hombre y del Ciudadano de 1789, y las subsecuentes declaraciones de derechos, que fueron solo eso, declaraciones de derechos, es decir, no tenían fuerza ejecutiva. Después de la Segunda Guerra Mundial, como consecuencia de los genocidios ocurridos, se empezaron a garantizar los derechos humanos y las personas tuvieron subjetividad para hacer valer los mismos, incluyendo el derecho a la vida. ${ }^{37}$

HоттоIS expuso desde su posición que, la participación de la Filosofía en la Bioética debe ser más formal que sustancial: debe cumplir roles de análisis metaético, corrección ló gica y regulación metodológica. La misión de los filósofos en bioética debe consistir en ser más bien "guardianes de la ética de la discusión", ${ }^{38}$

De este modo, queda claro que luego del análisis de esta postura del autor con sultado, para los articulistas la Bioética no es una ciencia porque no tiene axiomas claros, sino sapiencia, entendida como un discurso que se hace a través de la ciencia. También, se soporta esta determinación en que la bioética no tiene objeto, campo o tema de trabajo: tiene dilemas y problemas. Es concebida como un concepto polisémico que aún puede resistir muchos aportes desde otras ciencias como las humanidades y otras disciplinas y saberes. Por ello, la bioética es pluridisciplinar, se relaciona con técnicas médicas y biológicas; en segundo lugar, con

\footnotetext{
${ }^{36}$ Véa se, Pablo IV (2001)Carta Encíclica, Humanae Vitae. Sobre la transmisión de la vida humana. $1^{\text {ra }}$ edición, Editorial San Benito, Italia; Hart, H. (2003) Utilitarismo y derechos naturales. Universidad Externado de Colombia; Hervada, J. (2006) Síntesis de historia de la ciencia delDerecho natural. EditorialEUNSA. España. ${ }^{37}$ Gros Espiell, H. (2011) Bioderecho internacional, Enciclopedia de Bioderecho y Bioética, EditorialComares, España.

${ }^{38}$ Hottois, G. (1991) El paradigma bioético. Una Ética para la Tecnociencia, Editorial Anthropos, Barcelona.
} 
disciplinas llamadas a enfrentar sus puntos de vista, como la ética, el Derecho, la Filosofía o la Teología.

Con ello, se corrobora como la Bioética ostenta una tendencia normativa, cuyo análisis ético tiene dos vertientes: la primera trabaja sobre la clarificación y explicación de las posturas éticas, lo cual facilita el debate ético entre las personas involucradas en el problema; la segun da es más normativa y conduce a la toma práctica de decisiones. Hoy en día el derecho a la vida es un derecho fundamental reconocido por casi todas las constituciones modernas en forma expresa o tácita, ésta última forma de reconocimiento se da como derecho constitucional no escrito o dentro del bloque de constitucionalidad, por estar consagrado en alguna ley de derecho interno o internacional que tiene el rango de Ley Fundamental en los ordenamientos jurídicos.

Se puede aseverar, que la Bioética como disciplina autónoma surge a finales del siglo pasado como una necesidad de establecer un control social de las actividades sanitarias, médicas e investigadoras, de aquí su tránsito al bioderecho, el que permite su reconocimiento en norm as jurídicas.

Queda claro que, el derecho a la vida como todos los derechos fundamentales debe ser interpretado respetando los principios de la interpretación constitucional y de los derechos fundamentales, y no como cualquiera que sea su interpretación jurídica; la cual es proteger y defender lo más valioso que existe para cualquier hombre: su libertad y dignidad, debiendo respetar entonces los principios de coherencia, funcionalidad, eficacia, indubio pro libertate, pro homine, entre otros. ${ }^{39}$

\section{3 ¿Qué es entonces el Bioderecho?}

En relación al Bioderecho o Biojurídica como también se le llama, es la consecuencia del desarrollo de la bioética, en el campo de la actuación sanitaria a una legislación que institucionaliza un modelo de relación médico-paciente basada en los derechos del sujeto. Como consecuencia del desarrollo de la Bioética, no solo lleva a una legislación que in stitucion aliza un nuevo modelo de relación médico-paciente basada en los derechos del paciente. Se significa que dentro del contexto español se utilizó con mayor frecuencia el término de biojurídica y dentro del contexto americano se habló de Bioderecho. ${ }^{40}$

El Bioderecho es concebido como una disciplina que estudia la conducta de los seres humanos desde el punto de vista de la ética y de la ciencia jurídica, y, ante el desarrollo

\footnotetext{
${ }^{39}$ Véa se, Ferrajoli, L. (2007) Sobre los derechos fundamentales y sus ga rantías. CNDH, México, p. 8; Tealdi, J. (2008) Bioética de los derechos humanos. Investigaciones biomédicas y dignidad humana, UNAM, México, p . 59; Díez-Picazo, L. (2008) Sistema de derechos fundamentales. $3^{\text {ra }}$ edición, Editorial Thomson Civitas, España. ${ }^{40}$ Confróntese, Vila, M.(1995) Introducción a la biojurídica. Universidad Complutense de Madrid. España; Olano, H. (S.f) La biojurídica: suma de la bioética y de la acción de tutela. Revista Jurídica Piélagus Universidad Surcolombiana, pp.77-87; Aparisi Miralles, Á. (2007) Bioética, bioderecho y biojurídica. Anuario de Filosofía delDerecho No. 24. España.
}

Rev. Campo Juridico, barreiras-BA v.8 n.2, p. 140-174, Julio-Diciembre, 2020. 
científico tecnológico que ha alcanzado la humanidad, se encarga de establecer límites y regulaciones en el ámbito de las ciencias de la vida y de la salud. ${ }^{41}$

De modo que, el Bioderecho acentúa que los conflictos éticos y jurídicos surgidos en virtud de la investigación biocientífica deben ser abordados desde dos puntos de vista: los principios y las reglas. Además de lo señalado, y más allá de la regulación de la relación médico paciente, se desarrolla una legislación que va regulando otros aspectos de la activid ad médica, más en la línea investigadora que asistencial, que como también hemos ido viendo contribuye a configurar la posición del sujeto ante los avances científicos de la medicina, y que consagra otros derechos pensados más en relación con la noción misma de persona y su identidad como miembro de la especie humana. ${ }^{42}$

En consecuencia, se puede aseverar que como concepto el Bioderecho en su definición guarda una gran afinidad con la bioética, y el derecho y la justicia. Se trata, del estudio de los aspectos jurídicos de las mismas temáticas abordadas por la bioética, como: el comienzo de la persona humana; hay persona desde el momento de la concepción o solo podemos hablar de persona en el momento del nacimiento; la protección de la dignidad personal frente al avance tecnológico y biomédico, como en el caso de los pacientes en unidades de cuidados intensivos; la procreación asistida, lo mismo que la inseminación artificial o el alquiler de vientre; la relación sanitaria; el morir humano como elección individual, etc. Por otro lado, el Biodere cho, en otras ocasiones, remite a cuestiones relacionadas con la legislación referente a cuestiones biológicas vegetales, animales o humanas, y tiene en muchos casos una perspectiva más comercial, relacionada con la biotecnología y las patentes que se producen en este campo. ${ }^{43}$

Por tanto, el objeto del Bioderecho consiste en establecer un entorno jurídico para normar las relaciones del ser humano en su contex to tanto interno como externo; especialmente, y con los avances de los últimos años, trata temas como: intimidad genética, protección de identidad genómica, aborto, eutanasia, maternidad subrogada, entre otras. Es una respuesta jurídica a los avances científicos y tecnológicos de los últimos años y la necesidad de regulación de las situaciones nuevas que dichos avances nos representan; los reclamos del respeto a la dignidad y la libertad humana encuentran en el bioderecho un excelente aliado. Es interdisciplinar con otros

${ }^{41}$ Consúltese, Atienza, M.(1998) Juridificar la bioética. Isonomía. Revista de Teoría y Filosofía del Derecho No
8, México, pp.75-99; Romeo Ca sabona, C. (2011) Bioderecho y bioética. Enciclopedia de bioderecho y
bioética. Editorial Comares, España; Schaefer Rivabem, F. (2017) Bioderecho: ¿u na disciplin a a utóno ma?
Revista Bioética No 25, pp.282-289
${ }^{42}$ Confróntese, Abboud Castillo, N. y Pérez Gallardo, L. (2007) Las donaciones de órganos y tejid os. Sta tu s
legal, Bioética desdeuna perspectiva cubana. Editorial Acuario, La Habana; Gascón, M. (2008) Bioética,
principios, desafíos, debates. Editorial Alianza. España; Blázquez, N. (2010) Bioética y Biotanasia, Ed it orial
Visión Libros, España;
s3ara ello, confróntese, Oswald, U. (2002) El reordena miento de la natura leza: Impactos ambientales y
sociales de los transgénicos. La vida en venta: transgénicos, Patentes y Biodiversidad. EditorialBôll, Espa ña;
Velásquez, J. (2011) Elnecesario rescate de los conceptos naturaleza y naturaleza humana de cara a los retos de
la reflexión en la bioética y elbioderecho. Revista Facultad de derecho y ciencias políticas No 41, pp. $401-426$;
Gómez, J. (2012) Bioética y ecología: los valores de la naturaleza como norma moral. Editorial Síntesis.
España. Rev. Campo Juridico, barreiras-BA v.8 n.2, p. 140-174, Julio-Diciembre, 2020. 
campos del saber. Se integra a ciencias como la genética, la robótica, la nanotecnología, por los problemas que son objeto de su interés que surgen en estas ciencias con los avances que el siglo XXI sigue imponiendo al hombre como ser social en la web 2.0. ${ }^{44}$

El Bioderecho, surge como respuesta a los avances del progreso científico y tecnoló gico vinculados con la problemática de los seres vivientes, y representa una simbiosis entre la vida y el comportamiento del ser humano en su entorno natural, que se relaciona con to do aquello relativo a la salud y la dignidad. Es concebido como la respuesta jurídica a los problemas de la bioética; debemos dejar claro que no es una herramienta absolutamente técnica. Se convierte en el aliado más cercano de la Bioética y se convierte en su herramienta jurídica, para defender la humanidad de un tecnicismo y un cientificismo que en muchas ocasiones amenazan incluso nuestra propia supervivencia, de aquí la pertinencia de cumplir los principios. ${ }^{45}$

Por esta razón, se considera que la función que poseen los principios del Bioderecho es emplazar, a nivel legislativo y constitucional, un fundamento jurídico para la protec ción de la privacidad de la persona. Es la base de los bioderechos individuales, los cuales pueden ser descritos como la tensión entre los derechos individuales para con el propio cuerpo, la protección de esos derechos por parte del Estado, y la determinación de los límites de esos derechos. Ello significa que, el Bioderecho, entiende la autonomía individual como mediada por el espacio público. Por lo tanto, el bioderecho puede ser definido como una expresión de moralidad política (pública) e integridad legal, como se señala desde el Derecho Internacional y se desarrolla en la Ley fundamental.

De lo anterior señalado, se aprecia como la mayoría de los países europeos interpretan los principios del Bioderecho a la luz de los derechos humanos. De esta manera, el Bioderecho se constituye obligatoriamente en materia constitucional. La mayoría de las constituciones europeas protegen explícitamente la integridad y dignidad de la persona y algunas señalan los principios del bioderecho y sus implicaciones como susceptibles de ser interpretados constitucionalmente. Representa un referente valido para deliberar en torno a la viabilidad legal de los alcances de la biotecnología, especialmente acerca de aquellas técnicas biotecnológicas que van más allá de la terapia y, como tales, despliegan un entendimiento reduccionista y determinista del ser humano: por un lado, lo reducen a un conjunto de códigos genéticos que es

\footnotetext{
${ }^{44}$ Véa se, Flores, F. (2004) Bioderecho. Editorial Porrúa. México; Ollero, A. (2006) Bioderecho. Entre la vida y la muerte, Editorial Thomson Aranzadi. España; Figueroa, G. (2011) Bioderecho. Enciclopedia de Biodere cho y Bioética.EditorialComares, España; Mazo Álvarez,H. (2014)ElBioderecho: La respuesta jurídica a los problemas que plantea la bioética. Revista Producción + Limpia, No 9, pp.74-88; Schaefer Rivabem, F. (2017) Bioderecho: ¿una disciplina autónoma?Revista Bioética, No 25,pp.282-289

${ }^{45}$ Consúltese, Junquera De Estéfani, R. (2012) Derecho, Bioética y Bioderecho, un cruce de camin os para un derecho emergente: el derecho a ser informado en la asistencia biomédica. Dilemas bioéticos actuales: Investigación biomédica, principio y finalde la vida, EditorialDykinson, Madrid; Valdés, E. (2018) ¿Qué es el bioderecho? Propuesta metodológica y doctrinaria para resolver problemas jurídicos de últim a generación. Estudios a cerca del derecho de la salud II, Editorial Thomson Reuters-La Ley, Argentina.
} 
necesario descifrar y mejorar; por otro, buscan predeterminar la biología humana, modificando su composición genética. ${ }^{46}$

Por esta razón argüida, en 1993, la UNESCO crea el Comité Internacional de Bioética, y se producen documentos jurídicos como la Declaración Universal sobre el Genoma y los Derechos Humanos, en 1997; la Declaración Internacional sobre los Datos Genéticos Humanos, del 2003, y la Declaración Universal sobre Bioética y Derechos Humanos del 2005. ${ }^{47}$

\section{La Bioética y el Bioderecho en el ordenamiento jurídico cubano}

Iniciaremos el análisis señalando que al igual que en muchas partes de Latinoaméric a, la disciplina estudiada hace su entrada institucional en las carreras de las ciencias médicas. Por ende, la gestación, origen y evolución de la Bioética en Cuba lo marca el ciclo de conferencias realizadas por BRAVOMATARANO en el año 1983, a partir de los "Problemas filosóficos de la medicina" y concluyen en 1987; aunque se destaca en este estudio las tangencias con la disciplina desde otros saberes, sin dejar de reconocer los aportes anteriores de otros autores cubanos del siglo XIX o de inicio y mediados del XX cuyo pensamiento percibe puntos de convergencia con la propuesta potteriana. ${ }^{48}$

Sin embargo, algunos autores afirman que fue ACOSTA SARIEGO en artículo publicado en 1986, titulado "En torno a la orientación filosófica de la Bioética" es utilizada por vez primera, por un autor cubano en una memoria escrita el término bioética ${ }^{49}$ Retomando el estudio sobre el desarrollo de la Bioética en Cuba, se aprecia como coinciden varios autores, que la misma no ha sido periodizada aun de manera adecuada. Pero sí existen textos científicos que recogen los hechos que caracterizan a la bioética, los cuales aparecen ordenados cronológicamente, pero no se percibe en ellos escisiones por etapas, ni se percibe de manera diáfana que condicionantes inciden en el paso de una etapa a otra. ${ }^{50}$

Se destaca además la obra "Los árboles y el bosque", texto y contexto bioético ACOSTA SARIEGO y su tesis sobre el Pensamiento bioético cubano. Tendencias y características distintivas, las que en mayor profundidad muestran la descripción de los suce sos que han venido condicionando a la disciplina procura en las mismas revelar las tendencias del pensamiento bioético cubano. ${ }^{51}$

\footnotetext{
${ }^{46}$ Abboud Castillo, N. y Pérez Gallardo, L. (2007)Las donaciones de órganos y tejidos. Sta tus legal, Bioética desde una perspectiva cubana. Editorial Acuario, La Habana, Valdés, E. (2015) Bioderecho, daño genético y derechos humanos de cuarta generación, Boletín Mexicano de Derecho Comparado No. 144

${ }^{47}$ ONU (2005) Declaración Universal sobre Bioética y Derechos Humanos. Adoptada por la conferencia general de la UNESCO el 19 de octubre de 2011.

${ }^{48}$ Bra vo Matarano, E. (1998) La ética del científico en Cuba. Bioética desde una Perspectiva Cubana. Editorial Félix Varela. Cuba.

${ }^{49}$ Acosta Sariego, J. et al. (1997) Bioética desde una perspectiva cubana. Centro Félix Varela, La Habana.

${ }^{50}$ Acosta Sariego, J. et. al(1997)El escenario postmod erno de la Bioética. En Bioética desde una perspectiva cubana. Centro Felix Varela, La Habana.

${ }^{51}$ Acosta Sariego, J. (2009) Los árboles y el bosque. Texto y contex to bioético cubano. EditorialCentro Félix Varela.La Habana.
} 
Como consecuencia de lo acotado, se arguye que la trayectoria de la Bioética en Cuba no está condicionada por los mismos factores sociales que caracterizan otros contextos foráneos. Las particularidades desde el punto de vista ético, económico, cultural, jurídico, religioso, etc., abogan por una bioética que se ajusta a las circunstancias de un país económicamente actualizado a algunos avances científicos, pero con índices de educación y salu d comparables con los que muestran las naciones industrializadas y con una imagen de justicia y equidad, reconocidos desde el Bioderecho.

De modo que, el primer período caracterizado por la asimilar el nue vo saber analizado comprende el lapso temporal de 1983-1991, en el cual prevaleció el tratamiento de problemas éticos que se daban en la rama sanitaria sin aun profundizar en la Bioética como disciplina académica desde la ciencia del Derecho. Se destacan autores como FUnG RiVERón, quien caracteriza desde su posición la identidad de la bioética en su novedad y compleja urdimbre de interrelaciones: “...el saber bioético está en plena construcción...” uno de los elementos característicos de dicho saber es conocer la vinculación entre la concepción y la instrumentación, en lo cual se diferencia de gran parte de la filosofía contemporánea. Su carácter global y local lo emparentan de modo cercano con el ambiente, y padece de las mismas dificultades operacionales que aquejan a este último, a la vez que conjuga, también como él, lo teórico y lo empírico, lo absoluto y lo contaminado con ciencias diversas, la circularidad de sus conceptos y su papel mediatorio tanto horizontal como de modo vertical. ${ }^{52}$

Otro estudioso, que ha aportado a la elaboración del artículo es DELGADo DíAz, catalogado como el pionero en Cuba de la interpretación de la Bioética como un nuevo tipo de saber, ha sido capaz de darle contenido a ese aserto original de POTTER en un novedoso enfoque de cómo comprender el conocimiento a través del prisma de los valores y la integración del nuevo saber y la ruptura con la racionalidad clásica realizada en conjunto con la epistemología de segundo orden, el pensamiento de la complejidad y el holismo ambientalista. Es significativo que, la propuesta de un nuevo saber desde la práctica de la vida la bioética holística de Potter, coincidiera en su versión definitiva con las ideas elaboradas en el ambientalismo, y se proyectase así, como una ética ambiental, ecológica. ${ }^{53}$

En cuanto el progreso normativo que ha tenido el Bioderecho, conlleva a estudiar el ordenamiento jurídico, a partir del texto supremo

\footnotetext{
${ }^{52}$ Fung Riveron, T. (2002) La bioética: ¿un nuevo tipo saber? Bioética para la sustentabilidad. Editorial Acuario, La Habana.

${ }^{53}$ Delgado Díaz, C. (2002) Cognición, problema ambiental y bioética. Bioética. Para la sustentabilidad. Editorial Acuario. La Habana.
} 


\begin{tabular}{|c|c|c|}
\hline \multirow[t]{3}{*}{$\begin{array}{l}\text { Constitución de la } \\
\text { República de Cuba de } \\
1976\end{array}$} & $\begin{array}{c}\text { Articulo } \\
27\end{array}$ & $\begin{array}{l}\text { Para asegurar el bienestar de los ciudadanos, el Estado y la } \\
\text { sociedad protegen la naturaleza. Incumbe a los órganos } \\
\text { competentes y además a cada ciudadano velar porque sean } \\
\text { mantenidas limpias las aguas y la atmósfera, y que se proteja el } \\
\text { suelo, la flora y la fauna. }\end{array}$ \\
\hline & $\begin{array}{l}\text { Artículo } \\
\quad 42\end{array}$ & $\begin{array}{l}\text { Reciben asistencia médica en todas las instalaciones } \\
\text { hospitalarias }\end{array}$ \\
\hline & $\begin{array}{l}\text { Artículo } \\
\quad 49\end{array}$ & $\begin{array}{l}\text { Todos tienen derecho a que se atienda y proteja su salud. El } \\
\text { Estado garantiza este derecho: } \\
\text {-con la prestación de la asistencia médica y hospitalaria gratuita, } \\
\text { mediante la red de instalaciones de servicio médico rural, de los } \\
\text { policlínicos, hospitales, centros profilácticos y de tratamiento } \\
\text { especializado; } \\
\text {-con la prestación de asistencia estomatológica gratuita; } \\
\text {-con el desarrollo de los planes de divulgación sanitaria y de } \\
\text { educación para la salud, exámenes médicos periódicos, } \\
\text { vacunación general y otras medidas preventivas de las } \\
\text { enfermedades. En estos planes y actividades coopera toda la } \\
\text { población a través de las organizaciones sociales y de masas. }\end{array}$ \\
\hline \multicolumn{3}{|c|}{ Decreto Ley No. 54 de 19. Disposiciones Sanitarias Básica } \\
\hline \multicolumn{3}{|c|}{ Ley No. 41 de 1984, Ley de la Salud Pública } \\
\hline \multicolumn{3}{|c|}{ Decreto No. 139 de , Reglamento de la Ley de la Salud Pública } \\
\hline \multicolumn{3}{|c|}{ Ley No. 33 de Ley del Medio Ambiente y los Recursos Naturales } \\
\hline \multicolumn{3}{|c|}{ Ley No. 62, Código Penal } \\
\hline
\end{tabular}

La segunda etapa analizada, estuvo caracterizada por la institucionalización de la disciplina y abarca el espacio temporal entre 1990 y 2000 . Esto nos lleva a apreciar como la segunda mitad de la de década del 90' muestra un mayor acercamiento hacia las preocupaciones ambientales suscitado por la divulgación de la visión holística que enarbola POTTER sobre la disciplina, además, por la maduración que va adquiriendo el pensamiento bioético en nues tras academias. La perspectiva global y ambientalista adquiere en este período un rol protagónico por la profundidad de sus análisis y por lo significativo de sus aportes al debate bioético nacional. Por lo que se refiere al orden normativo, se emiten las disposiciones jurídicas, en el cual se reforma el texto supremo 


\begin{tabular}{|c|c|c|}
\hline \multirow[t]{2}{*}{$\begin{array}{l}\text { Constitución de la República } \\
\text { de Cuba de 1976, reformada } \\
\text { en } 1992\end{array}$} & $\begin{array}{c}\text { Articulo } \\
27\end{array}$ & $\begin{array}{l}\text { El Estado protege el medio ambiente y los recursos } \\
\text { naturales del país. Reconoce su estrecha vinculación con } \\
\text { el desarrollo económico y social sostenible para hacer más } \\
\text { racional la vida humana y a segurar la supervivencia, el } \\
\text { bienestar y la seguridad de las generaciones actuales y } \\
\text { futuras. Corresponde a los órganos competentes aplicar } \\
\text { esta política. } \\
\text { Es deber de los ciudadanos, contribuir a la protección } \\
\text { del agua, la atmósfera, la conservación del suelo, la } \\
\text { flora,la fauna y todo el rico potencial de la naturaleza. }\end{array}$ \\
\hline & $\begin{array}{c}\text { Articulo } \\
50\end{array}$ & $\begin{array}{l}\text { Todos tienen derecho a que se atienda y proteja su salud. } \\
\text { El Estado garantiza este derecho: con la prestación de la } \\
\text { a sistencia médica y hospitalaria gratuita, mediante la red de } \\
\text { instalaciones de servicio médico rural, de los policlínicos, } \\
\text { hospitales, centros profilácticos y de tratamiento } \\
\text { especializado; con la prestación de asistencia } \\
\text { estomatológica gratuita; con el desarrollo de los planes de } \\
\text { divulgación sanitaria y de educación para la salud, } \\
\text { exámenes médicos periódicos, vacunación general y otras } \\
\text { medidas preventivas de las enfermedades. En estos planes } \\
\text { y actividades coopera toda la población a través de las } \\
\text { organizaciones de masas y sociales. }\end{array}$ \\
\hline \multicolumn{3}{|c|}{ Decreto Ley No. 54 de 1982. Disposiciones Sanitarias Básicas } \\
\hline \multicolumn{3}{|c|}{ Ley No. 41 de 1984. Ley de la Salud Pública } \\
\hline \multicolumn{3}{|c|}{ Ley No. 62 de , Código Penal } \\
\hline \multicolumn{3}{|c|}{ Decreto No. 139 de 1989. Reglamento de la Ley de la Salud Pública } \\
\hline \multicolumn{3}{|c|}{ Ley No. 81 de 1997, Ley del Medio Ambiente } \\
\hline
\end{tabular}

En este último momento de evolución del pensamiento bioético que comprende los años del 2000 al 2020, se aprecia en el ordenamiento jurídico otra reforma del tex to supremo

\begin{tabular}{|l|l|l|}
\hline $\begin{array}{l}\text { Constitución de la República de } \\
\text { Cuba de 1976, reformada 2002 }\end{array}$ & Articulo 27 & $\begin{array}{l}\text { El Estado protege el medio ambiente y los recursos } \\
\text { naturales del país. Reconoce su estrecha vinculación } \\
\text { con el desarrollo económico y social sostenible para } \\
\text { hacer más racional la vida humana y asegurar la } \\
\text { supervivencia, el bienestar y la seguridad de las } \\
\text { generaciones actuales y futuras. Corresponde a los } \\
\text { órganos competentes a plicar esta política. Es deber de } \\
\text { los ciudadanos, contribuir a la protección del agua, } \\
\text { la atmósfera, la conservación del suelo, la flora, la } \\
\text { fauna y todo el rico potencial de la naturaleza. }\end{array}$ \\
\hline Ley No. 62, Código Penal & \\
\hline Ley No. 41 de 1984. Ley de la Salud Pública \\
\hline Ley No. 81 de 1997. Ley del Medio Ambiente. \\
\hline Decreto Ley No. 54 Disposiciones Sanitarias Básicas \\
\hline
\end{tabular}

Como continuidad, en la actualización del modelo económico social, se aprueba una nueva Constitución en el ordenamiento jurídico cubano, y se emiten nuevas disposiciones legales concomitantes con la Bioética y el Bioderecho 


\begin{tabular}{|c|c|c|}
\hline \multirow[t]{10}{*}{$\begin{array}{l}\text { Constitución de la } \\
\text { República de Cuba de } \\
2019\end{array}$} & Artículo 8 & $\begin{array}{l}\text { Lo prescrito en los tratados internacionales en vigor para la } \\
\text { República de Cuba forma parte o se integra, según corresponda, } \\
\text { al ordenamiento jurídico nacional. La Constitución de la } \\
\text { República de Cuba prima sobre estos tratados internacionales. }\end{array}$ \\
\hline & Artículo 40 & $\begin{array}{l}\text { La dignidad humana es el valor supremo que sustenta el } \\
\text { reconocimiento y ejercicio de los derechos y deberes } \\
\text { consagrados en la Constitución, los tratados y las leyes. }\end{array}$ \\
\hline & Artículo 41 & $\begin{array}{l}\text { El Estado cubano reconoce y garantiza a la persona el goce y el } \\
\text { ejercicio irrenunciable, imprescriptible, indivisible, universal e } \\
\text { interdependiente de los derechos humanos, en correspondencia } \\
\text { con los principios de progresividad, igualdad y no } \\
\text { discriminación. Su respeto y garantía es de obligatorio } \\
\text { cumplimiento para todos. }\end{array}$ \\
\hline & Artículo 42 & $\begin{array}{l}\text { Todas las personas son iguales ante la ley, reciben la misma } \\
\text { protección y trato de las autoridades yozan de los mismos } \\
\text { derechos, libertades y oportunidades, sin ninguna } \\
\text { discriminación por razones de sexo, género, orientación } \\
\text { sexual, identidad de género, edad, origen étnico, color de la } \\
\text { piel, creencia religiosa, discapacidad, origen nacional o } \\
\text { territorial, o cualquier otra condición o circunstancia } \\
\text { personal que implique distinción lesiva a la dignidad } \\
\text { humana. } \\
\text { Todas tienen derecho a disfrutar de los mismos espacios } \\
\text { públicos y establecimientos de servicios. Asimismo, reciben } \\
\text { igual salario por igual trabajo, sin discriminación alguna. La } \\
\text { violación del principio de igualdad está proscrita y es } \\
\text { sancionada porla ley. }\end{array}$ \\
\hline & Artículo 46 & $\begin{array}{l}\text { Todas las personas tienen derecho a la vida, la integridad física } \\
\text { y moral, la libertad, la justicia, la seguridad, la paz, la salud, la } \\
\text { educación, la cultura, la recreación, el deporte y a su desarrollo } \\
\text { integral. }\end{array}$ \\
\hline & Artículo 54 & $\begin{array}{l}\text { El Estado reconoce, respeta y garantiza a las personas la } \\
\text { libertad de pensamiento, conciencia y expresión. La } \\
\text { objeción de conciencia no puede invocarse con el propósito } \\
\text { de evadir el cumplimiento de la ley o impedir a otro su } \\
\text { cumplimiento o el ejercicio de sus derechos. }\end{array}$ \\
\hline & Artículo 69 & $\begin{array}{l}\text { El Estado garantiza el derecho a la seguridad y salud en el } \\
\text { trabajo mediante la adopción de medidas adecuadas para la } \\
\text { prevención de accidentes y enfermedadesprofesionales. }\end{array}$ \\
\hline & Artículo 72 & $\begin{array}{l}\text { La salud pública es un derecho de todas las personas y es } \\
\text { responsabilidad del Estado garantizar el acceso, la } \\
\text { gratuidad y la calidad de los servicios de atención, } \\
\text { protección y recuperación. El Estado, para hacer efectivo este } \\
\text { derecho, instituye un sistema de salud a todos los niveles } \\
\text { accesible a la población y desarrolla programas de prevención y } \\
\text { educación, en los que contribuyen la sociedad y las familias. La } \\
\text { ley define el modo en que los servicios de salud se prestan. }\end{array}$ \\
\hline & Artículo 75 & $\begin{array}{l}\text { Todas las personas tienen derecho a disfrutar de un medio } \\
\text { ambiente sano y equilibrado. } \\
\text { El Estado protege el medio ambiente y los recursos naturales } \\
\text { del país. Reconoce su estrecha vinculación con el desarrollo } \\
\text { sostenible de la economía y la sociedad para hacer más } \\
\text { racional la vida humana y asegurar la supervivencia, el } \\
\text { bienestar y la seguridad de las generaciones actuales y } \\
\text { futuras. }\end{array}$ \\
\hline & Artículo 76 & $\begin{array}{l}\text { Todas las personas tienen derecho al agua. } \\
\text { El Estado crea las condiciones para garantizar el acceso al agu a } \\
\text { potable y a su saneamiento, con la debida distribución y el uso } \\
\text { racional. }\end{array}$ \\
\hline
\end{tabular}




\begin{tabular}{|c|c|c|}
\hline & Artículo 77 & $\begin{array}{l}\text { Todas las personas tienen derecho a la alimentación sana y } \\
\text { adecuada. El Estado crea las condiciones para fortalecer a } \\
\text { seguridad alimentaria de toda la población. }\end{array}$ \\
\hline \multicolumn{3}{|c|}{ Ley No. 41 de 1984.Ley de la Salud Pública } \\
\hline \multicolumn{3}{|c|}{ Ley No. 59 de 1987. Código Civil } \\
\hline \multicolumn{3}{|c|}{ Ley No. 62 de 19 , Código Penal } \\
\hline \multicolumn{3}{|c|}{ Ley No. 81 de 1997, Ley del Medio Ambiente } \\
\hline \multicolumn{3}{|c|}{ Decreto No. 139 de 1989. Reglamento de la Ley de la Salud Publica } \\
\hline \multicolumn{3}{|c|}{ Decreto Ley No. 54 de 1982. Disposiciones Sanitarias Básicas } \\
\hline \multicolumn{3}{|c|}{ Ley No. 124 de 2017. Ley de Aguas terrestres } \\
\hline Ley No. 118 de 2014. & ey de la Inver & ón Extranjera \\
\hline
\end{tabular}

2.1 La formación jurídica en Bioética y Bioderecho en la carrera de Derecho en la Universidad de Granma desde la disciplina de Derecho Civil y Familia

El siguiente punto de análisis, para demostrar cómo se ha ejecutado la formación académica en Bioética y Bioderecho; al revisar la bibliografía para conformar el artículo, se aprecia como inicia su inclusión en el curso académico 1978-79 en la asignatura Ética y Deontología Médica en los estudios de ciencias médicas en la nación cubana. De modo que, aparece por primera vez en la historia de la educación médica cubana como una materia independiente para todas las carreras en los estudios de las ciencias de la salud. ${ }^{54} \mathrm{La}$ misma era impartida por profesionales de las ciencias médicas y juristas del sistema de salud en las aulas universitarias.

En consecuencia, en el campo del Derecho de la Salud, en relación al Bioderecho, se ha refrendado la voluntad de protección del embrión y la maternidad, en el establecimiento de unos mínimos exigibles a todos, que permitan la libertad de elección sin perjudicar a terceros o al bien común. Los límites del aborto electivo los han fijado las regulaciones adminis trativas del Ministerio de Salud Pública (MINSAP).

En la revisión de los actos administrativos internos emitidos por el MINSAP, se valora por los autores del artículo, como fijan lo que se considera en Cuba como la frontera de la sustantividad constitucional del embrión y, por tanto, de la obligación de los deberes de justicia y no maleficencia para con él; representa un curso intermedio de acción entre las posiciones extremas en juego a modo de solución en tanto la ciencia y la moral continúan hurgando en la esencia del origen de la vida humana.

Otra faceta es que el MINSAP ha dispuesto también en actos administrativos en los conflictos éticos del principio de la vida se expresa en el uso de las tecnologías que favorecen la reproducción humana en relación a la bioética. En Cuba las técnicas de reproducción humana asistida por el bioderecho están a disposición de todas las parejas que lo requieran. La actitud generalizada se inclina a aceptar la licitud moral del uso de estas técnicas en tanto la infertilidad puede ser asumida como discapacidad y fuente de sufrimiento para la pareja, así como la

\footnotetext{
${ }^{54}$ Martínez Gómez, J. (2015) Ética profesional y Deontología médica: una reflexión sobre el estado de la cuestión en Cuba, Revista Bioética

Rev. Campo Juridico, barreiras-BA v.8 n.2, p. 140-174, Julio-Diciembre, 2020. 
búsqueda de ayuda médica como constitutiva de acto de amor conyugal. El Sistema Nacional de Salud Pública garantiza el acceso universal a todos los que requieran de estas tecnologías.

Por tanto, se justiprecia que en Cuba las técnicas de reproducción humana asistida por las regulaciones del Bioderecho están a disposición de todas las parejas que lo requieran. La actitud generalizada se inclina a aceptar la licitud moral del uso de estas técnicas en tanto la infertilidad puede ser asumida como discapacidad y fuente de sufrimiento para la pareja, así como la búsqueda de ayuda médica como constitutiva de acto de amor conyugal.

Otro de los temas bioéticos que preocupó y ocupó a los autores cubanos que han estudiado el tema de la Bioética fue el de la determinación de la muerte a inicios del siglo XXI, el proceso del morir y el sustento moral de las decisiones médicas al final de la vida. De ahí la trascendental importancia de la promulgación de la Resolución No 90 del MINSAP del 2001, acerca de la determinación de la muerte que resultó consecuencia directa de este debate bioético y del bioderecho. De modo que, este instrumento legal se señala que viene a llenar cierto vacío, dado que el Código Civil cubano ${ }^{55}$, en lo que algunos juristas consideran un enfoque legislativo muy avanzado dejado en manos del MINSAP en relación a la adopción de los criterios pertinentes para el diagnóstico de la muerte humana.

Lo validan los estudios de varios autores que han abordado el tema desde varios saberes como TeJedA del PRAdo ${ }^{56}$, TORRES ${ }^{57}$, FREYRE $^{58}$, FunES-MonZOTE ${ }^{59}$, entre otros. En consonancia con este proceso ocurrido en el MINSAP, en la carrera de Derecho luego de haber transitado por profundas transformaciones curriculares en modificaciones de los Planes de Estudio por los planes “A”, "B", “C”, "C" perfeccionado y plan " $D$ ", caracterizad a por el perfeccionamiento continúo de la Educación Superior cubana (MES). La asignatura de Bioética y Derecho Civil y Familia, aparece por vez primera en el Plan de Estudios D del MES en su malla curricular ${ }^{60}$, con un fin, fomentar la formación jurídica en los temas bioéticos y del Bioderecho, con la cualidad de ser una materia optativa, fuera del currículo básico, vinculada a la Disciplina de Derecho Civil y Familia.

En este sentido, en la revisión de bibliografía para el articulo, se constata la evidencia de los autores cubanos que han incursionado en los temas desde la teoría en relación a la Bioética y el Bioderecho desde las ciencias jurídicas, como PÉREZ GALLARDO ${ }^{61}$, MARTínEZ GÓMEZ ${ }^{62}$, VALdÉs DíAZ ${ }^{63}$, Coll De Pestaña ${ }^{64}$, VILLAVElla ARMENGOL ${ }^{65}$, entre otros.

\footnotetext{
${ }^{55}$ Ley No. 59 de 1987, Código Civil.

${ }^{56}$ Tejeda delPrado, L. (1999) Identidad y crecimiento humano. Editorial Gente Nueva. La Habana.

${ }^{57}$ Torres, R. (2001) Glosario de bioética. Editorial Acuario. La Habana.

${ }^{58}$ Freyre, E. (2004) La bioética: enfoque imprescindible. Por una nueva ética. Editorial Félix Varela. La Habana.

${ }^{59}$ Funes-Monzote, F. (2009) Transgénicos: ¿Qué se ga na y qué se pierde? Tex tos para un deba te en Cuba, EditorialFélix Varela, La Habana.

${ }^{60}$ Plan de Estudios D del Ministerio de Educación Superior

${ }^{61}$ Abboud Castillo, N. y Pérez Gallardo, L. (2007) Las donaciones de órganos y tejidos. Status legal, B i oética desde una perspectiva cubana. Editorial Acuario, La Habana.
} 
De modo que, en su proceso formativo, queda demostrado que el estudiante de la carrera de Derecho, recibe los contenidos en una asignatura optativa, la que se imparte en el $3^{\text {er }}$ año de la carrera en el Plan de estudios E con 48 horas lectivas ${ }^{66}$, se abordan temas vinculados a la parte introductoria de la bioética a partir de: la Bioética como interdisciplina jurídica, concepto, antecedentes para el Derecho. Principios generales, justicia y no maleficencia, autonomía de la voluntad y beneficencia. Relación con las llamadas “ciencias de la vida”. Vinculación con el Derecho Civil y Familia, los derechos inherentes a la personalidad. Dilemas bioéticos contemporáneos. La transexualidad, el derecho a su propia imagen.

Un segundo tema, aborda: Los dilemas entorno a los Derechos inherentes a la personalidad desde una perspectiva Bioética, sus contenidos se centran en la determinación de la personalidad jurídica civil en la actualidad tecnológica. Los dilemas del inicio de la vida, la protección del concebido, regulaciones sobre la protección del embrión, situación internacional. El diagnóstico de la muerte, el momento de certificación legal de la muerte, concepciones contemporáneas acerca de la muerte encefálica, confirmación de la muerte, implicaciones éticas y jurídicas. Situación internacional acerca de la muerte encefálica. El trasplante de órgan os, tejidos y sustancias separadas del cuerpo, características, visión desde el Derecho y la Filosofía. Situación legislativa del trasplante de órganos en Cuba. Los dilemas al fin de la vida, la eutanasia, la muerte asistida o muerte digna. El consentimiento informado. El derecho a la integridad física. El rol del jurista ante el dilema bioético.

El tercer tema, denominado: Bioética y Derecho de Familia. La reproducción humana asistida, implicaciones éticas y jurídicas. Se analizan contenidos a partir del Derecho de Familia en relación con la Bioética. La reproducción humana asistida, nuevas técnicas reproductivas que irrumpen las instituciones del Derecho de Familia. Los sujetos de la reproducción humana asistida, la determinación de su acceso, el caso de la esterilidad. Derechos fundamentales v/s derechos individuales? El nexo biológico y el nexo jurídico, la verdad biológica y la filiación paterna en la reproducción humana asistida. La fertilización postmorten. Dilemas en torno a la fertilización in-vitro. Situación jurídica del donante en la fertilización in-vitro. Peculiaridades de la donación de gametos, la donación de ovocitos y semen. Relación del donante con el concebido, relación entre el donante y el receptor. El anonimato del donante. La maternidad subrogada, concepto, características y posturas filosóficas. Maternidad genética y maternidad uterina. El dilema entre autonomía y justicia, diversas posiciones legislativas. Posición

\footnotetext{
${ }^{62}$ Martínez Gómez. J (2015) Ética profesional y deontología médica: una reflexión sobre el estado de la cuestión en Cuba, Revista Bioética, Colombia.

${ }^{63}$ Valdés Díaz, C. (2012) Del derecho a la vida y los derechos sexuales y reproductivos, ¿configuración armónica o lucha de contrarios? Revista IUS N ${ }^{\circ} 29$. México.

${ }^{64}$ Coll De Pestaña, I. (2002) Análisis crítico sobre los efectos deldesafío genético en el bienestar de los niños, Memorias del XII Congreso Internacional de Derecho de Fa milia, MINJUS, La Habana, p. 160.

${ }^{65}$ Villabella ArmengoL, C. (2002) La axiología de los derechos humanos en Cuba. Temas de Derecho Constitucional cubano, Félix Varela, La Habana, pp. 291-300.

${ }^{66}$ Plan de Estudios E (2017) Ministerio de Educación Superior de la Republica de Cuba.
} 
subyacente de la legislación cubana y estado de la reproducción humana asistida en Cuba. El rol del jurista.

En el cuarto tema, se abordan contenidos vinculados a la argumentación de juicios bioéticos a partir de la ética profesional a la Bioética aplicada. La condición humana del jurista como eje integrador de su realización profesional. La justicia, la responsabilidad normativa y el deber profesional. Relación entre lo absoluto y lo relativo de acuerdo al principio de no maleficencia. La autonomía de la voluntad, como principio del Derecho Civil y de la Bioética, génesis conceptual y aplicabilidad profesional. Autonomía del criterio. La reflexión y el diálogo como herramientas de análisis bioético. El principio de beneficencia y el buen actuar. El sentido de lo lícito, lo bueno y lo justo. Las buenas prácticas y el deber profesional. La hermenéu tica jurídica y la convicción profesional como fuentes de la argumentación bioética.

Estos temas permiten a criterio de los articulistas aseverar que, el bioderecho tiene un papel fundamental que cumplir en la bioética. La ética por sí sola no alcanza para asegurar el respeto de la persona y la vigencia de los derechos humanos. Toda vezque la Bioética, por su compendio de conocimiento y contenidos interdisciplinarios, procura hoy dar respuesta a los diversos dilemas éticos que plantea el empleo de modernas tecnologías biomédicas en el amplio espectro de la dignidad y calidad de la vida, la integridad física, psíquica y espiritual de la persona, y la atención y cuidado de su salud. La Bioética debe estar al servicio del hombre y no el hombre al servicio de la bioética, todo ello enfocado en el derecho a la vida, salud, integridad física y el respeto a la dignidad de la persona humana.

En su desarrollo, el Plan de estudios E de la carrera de Derecho del MES ${ }^{67}$, se demuestra que como asignatura optativ a estos contenidos deberán dar respuesta a la necesidad de concebir desde la enseñanza de pregrado un sistema de formación continua de los profesionales, diseñado partiendo de la distinción de los contenidos a impartir en la enseñanza de pre y postgrado, p ara lo que se requiere de una mejor determinación de las invariantes y su posterior amplitud en un proceso ascendente de superación profesional del jurista. ${ }^{68}$

Todos estos elementos abordados up supra luego de la sistematización realizada, permiten argumentar a los articulistas la necesidad de en cumplimiento del objetivo trazado demostrar la pertinencia de la actualización de los contenidos de la materia optativa Bioética y Derecho Civil y Familia, en cada período lectivo que se desarrolle la materia por su carácter interdisciplinar con temas como:

- La objeción de conciencia en los procederes médicos y sanitarios en relación a los derechos de los médicos, tema vinculado a la tradición bíblica. En la tradición ético-jurídica

\footnotetext{
${ }^{67}$ Plan de estudios E (2017) de la carrera de Derechodel MES. La Habana.

${ }^{68}$ Antúnez Sánchez, A. \& Rondón Valdés, J. (2016) La formación de habilida des en los estudiantes de la carrera de Derecho. Mapas conceptuales. aprendizaje cooperativo. Un recurso indispensable en la formación universitaria, Universidad de Valencia, España.
} 
occidental, la objeción de conciencia se basa en que todo ser humano tiene derecho a la "libertad" de conciencia, en correspondencia con la Declaración de los Derechos Humanos. ${ }^{69}$

- La ciencia genómica y los paradigmas de la biotecnología como $3^{\text {ra }}$ Revolución Industrial dentro de la tecnociencias para el Bioderecho. El campo de acción del conocimiento geonómico se extiende a todos los seres vivos: animales, plantas y seres humanos, con el fin de mejorarlos, modificarlos o manipularlos, su aplicación en la salud humana, la medicina genómica, predictiva, molecular, reparativa y antienvejecimiento.

- Los derechos de los animales, transgénesis y enfermedades

- El poder transformador del impacto ambiental y social (económico y cultural) de sus aplicaciones

- La ingeniería genética en el siglo XXI y el Bioderecho

- La huella genética como prueba biológica en el Bioderecho

- La patentabilidad de las invenciones tecnológicas en el Bioderecho

- La información genética y el patrimonio genético: dimensiones de la intimidad personal y familiar

- La genealogía del Bioderecho y su desarrollo en el ordenamiento jurídico cubano

- Las Tecnologías de la Informática y las Comunicaciones y su impacto en el desarrollo de la Bioética y el Bioderecho en la web 2.0 con el uso de la internet de las cosas IoE, el Bid Data, Cloud computing, Open Data, la Realidad aumentada.

- La ovodonación y el Bioderecho en Cuba.

- El uso de la robótica en los procederes médicos y el Bioderecho.

En consecuencia, en la carrera de Derecho en la universidad de Granma hay que re saltar de manera puntual que en las tres modalidades de estudios que interactúan en el modelo del curso diurno, por encuentros y a distancia, en la asignatura han sido desarrollados los contenidos en la actividad formativa por profesores de Derecho de la Disciplina de Derecho Civil y el Médico Legal, los que forman parte del claustro académico. La que esta requerida de su actualización constante.

\section{Conclusiones}

Los fundamentos filosófico jurídicos de la Declaración Universal de los Derechos Humanos desde el Derecho Internacional, expresan con rigor y profundidad las cuestiones fundamentales acerca de los derechos del hombre, enuncia con claridad que se trata de derechos inherentes al ser humano desde el ámbito internacional. La Bioética surge como un inten to de

\footnotetext{
${ }^{69}$ Consúltese, Casado, M. (2009) Fundamentos éticos de las regulaciones sanitarias, objeción de conciencia y normativa bioética española. Dimensiones éticas de las regulaciones en salud. CIEB. Santiago de Chile, pp. 4360; Mautone, M. y Rodríguez Almada, H. (2013) Objeción de conciencia en elámbito de la sa lud. Re vista Médica Uruguaya $\mathrm{N}^{\circ} 29$, Uruguay, pp.40-42
} 
establecer un "puente" entre el saber científico y el saber humanís tico-moral, este puente se establece entonces como el único camino de solución posible ante el proceso científico y tecnológico indiscriminado que pone en peligro la humanidad y su propia supervivencia.

La Bioética como disciplina, desde un enfoque plural, pone en relación el co no cimi en to del mundo biológico con la formación de actitudes y políticas encaminadas a conseguir el bien social. El Derecho y la Bioética se han unido para dar pie a una nueva disciplina jurídica que sistematiza y da coherencia jurídico-ética a las nuevas realidades que emergen del ámbito de la conducta humana conocida como Bioderecho.

La Bioética lucha en favor del respeto por los derechos humanos, de los animales y del ambiente; propugna por la prevalencia del individuo frente al interés exclusivo de la socieda d o de la ciencia, es transdisciplinaria, global y flexible, se convierte en una excelente oportunidad para que cambie el modo de actuar con el objetivo de potenciar la vida sobre el planeta.

La asignatura Bioética y Derecho Civil que se imparte en la Carrera de Derecho de la Universidad de Granma tiene una vital importancia en la formación integral del profesional, debido a que contribuye a la creación y fortalecimiento de los valores humanismo y respeto a la dignidad humana, lo que conlleva a un ejercicio adecuado de las funciones del jurista en la sociedad actual.

Por otra parte, es necesaria una actualización de los contenidos que se imparten en la asignatura, a raíz de la implementación de un nuevo Plan de Estudios (“E”) que contextualiza el proceso de actualización del ordenamiento jurídico cubano, y con ello la revitalización de normas jurídicas en materia de Bioética y Bioderecho.

\section{Referencias}

AA. VV. (2007) Bioética y medio ambiente, Editorial Félix Varela, La Habana.

Abel I Fabre, F. (2001) Bioética: Orígenes, presente y futuro, Editorial Mapfre. España.

Abboud Castillo, N. y Pérez Gallardo, L. (2007) Las donaciones de órganos y tejidos. Status legal, Bioética desde una perspectiva cubana. Editorial Acuario, La Habana.

Andruet, A. (2007) Bioética y Derechos Humanos, Editorial de la Universidad Católica de Córdoba.

Acosta Sariego, J. et al. (1997) Bioética desde una perspectiva cubana. Centro Félix Varela. La Habana.

Acosta Sariego, J. et. al. (1997) El escenario postmoderno de la Bioética. En Bioética desde una perspectiva cubana. Centro Félix Varela. La Habana.

Acosta Sariego, J. (2009) Los árboles y el bosque. Texto y contexto bioético cubano. Centro Félix Varela. La Habana.

Rev. Campo Juridico, barreiras-BA v.8 n.2, p. 140-174, Julio-Diciembre, 2020. 
Acosta Sariego, J. (1998) Tesis de maestría: Transculturación e identidad en la perspectiva cubana de la bioética. Universidad de Chile. Santiago de Chile.

Amor Pan, J. (2005) Introducción a la bioética. Editorial PCC. España.

Antúnez Sánchez, A. (2011) El consentimiento informado en el Derecho Médico cubano. Revista Ámbito Jurídico. Brasil.

Antúnez Sánchez, A. (2011) La relación médico-paciente, bioética, atención primaria de salud. Revista Ciencias. España.

Antúnez Sánchez, A. (2017) La enseñanza virtual del Derecho. Una aproximación en la universidad cubana, Revista Pedagogía universitaria y didáctica del Derecho. Chile.

Antúnez Sánchez, A. (2019) La bioética en el pensamiento del legislador ecuatoriano en la protección de la Pacha Mama. Revista Derecho \& Paz No. 40. Brasil.

Antúnez Sánchez, A. (2019) La contaminación ambiental en los acuíferos del Ecuador. Necesidad de su reversión desde las políticas públicas con enfoque bioético. Revista de Derecho Ambiental. Doctrina, jurisprudencia, legislación y práctica N $^{\text {o. }}$ 57. Editorial Abeledo Perrot. Argentina.

Aguiar-Guevara, R. (2008) Tratado de Derecho Médico. Editorial Legislec. Venezuela.

Agenda 2030 (2018) Los objetivos de desarrollo sostenible. Una oportunidad para América Latina y el Caribe, CEPAL, Chile.

Albert, M. (2013) ¿Hacia un bioderecho universal? Bioderecho en acción y funcionalización del valor de la vida humana. Cuadernos de Bioética $\mathrm{N}^{\circ} .24$

Albarellos, L. (2007) Bioética con trazos jurídicos. Editorial Porrúa. México.

Albaladejo, M. (2002) Derecho Civil, Introducción y derecho de la persona, Editorial Bosch, Barcelona.

Álvarez del Río A. y Rivero, P. (2009) El desafío de la bioética. Editorial Fondo de cultura económica. México.

Alexy, R. (1993) Teoría de los derechos fundamentales. Centro de Estudios Constitucionales, España.

Alegre Martínez, M. (2011) El Derecho Constitucional al servicio de la persona: la protección a los más vulnerables y los nuevos derechos. Revista de Derecho Políticos No 80.

Andorno, R. (1998) Bioética y dignidad de la persona, Editorial Tecnos. España.

Aparisi Miralles, Á. (2007) Bioética, bioderecho y biojurídica. Anuario de Filo sofía del Derecho $\mathrm{N}^{\circ} \cdot 24$

Aparisi Miralles, Á. (2013) El principio de la dignidad humana como fundamento de un bioderecho global. Cuadernos de Bioética No ${ }^{\circ} .24$

Aramini, M. (2007) Introducción a la bioética. Editorial San Pablo. Colombia. 
Armas, L. (2011) El desarrollo curricular en la carrera de Derecho, Editorial Pueblo y Educación, La Habana.

Aramini, M. (2001) Introduzione alla bioética, Editore Giuffrè, Milano.

Atienza, M. (2004) Bioética, derecho y argumentación. Editorial Themis. Bogotá.

Álvarez de Zayas, R. (2004) Interdisciplinariedad: Una aproximación desde la enseñanza-aprendizaje de las ciencias. Compilación, Editorial Pueblo y Educación. La Habana.

Babini, J. (2000) Historia de la medicina, Editorial Gedisa. Barcelona.

Barrio Maestre, J. (2001) Analogías y Diferencias entre ética deontológica y bioética. Manual de Bioética, Editorial Ariel, España.

Bravo Matarano, E. (1998) La ética del científico en Cuba. Bioética desde una perspectiva cubana. Editorial Félix Varela. Cuba.

Bobbio, N. (1991) El tiempo de los derechos, Editorial Sistema. Madrid.

Boladeras Cucurella, M. (1999) Bioética, Editorial Síntesis. España.

Becerra-Ramírez, M. (2013) Derecho y Medicina. Editorial ASPE. México.

Blázquez, N. (2010) Bioética y Biotanasia. Editorial Visión Libros. España.

Blázquez, N. (2000) Bioética, la nueva ciencia de la Vida. Editorial BAC. España España.

Casado González, M. (1996) Materiales de Bioética y Derecho. Editorial CEDECS.

Casado González, M. (1998) Bioética, derecho y sociedad. Editorial Trotta. España.

Casado González, M. et. al. (1998) Los Derechos Humanos como marco para el Bioderecho y la Bioética. Derecho Biomédico y Bioética. Editorial Comares. España.

Casado González, M. (2011) Sobre las relaciones entre la bioética y el derecho, Revista Bioética $\mathrm{N}^{\circ} 1$, Brasil.

Casado González, M. et al. (2000) Estudios de Bioética y Derecho. Editorial Tirant lo Blanch. España.

Casado González, M. (2010) Bioética y Nanotecnología, Editorial Civitas. España.

Casado, M y González Duarte, R. (1999) Los retos de la genética en el siglo XXI: genética y bioética. Editorial Universidad de Barcelona. España.

Camacho Barreiro, A. \& Ariosa Roche, L. (2000) Diccionario de términos ambientales, Editorial Acuario. La Habana.

Cobas Cobiella, M. (2014) El aprendizaje cooperativo: una competencia imprescindible para la formación de los juristas, Revista Boliviana de Derecho, Bolivia, pp.604-621.

Corral García, E. (2013) El lenguaje bioético de la normativa y jurisprudencia sobre problemas biojurídicos. Cuadernos de Bioética $\mathrm{N}^{\circ} .24$ 
Couceiro-Vidal, A. (2008) Enseñanza de la bioética y planes de estudio basados en competencias. Editorial Viguera. España.

Copleston, F. (1969) Historia de la filosofía. Editorial Ariel. España.

Ciccone, L. (2005) Bioética. Historia. Principios. Cuestiones. Editorial Palabra. España.

Darío Bergel, S. (2002) Los Derechos Humanos entre la Bioética y la Genética. Acta Bioethica $\mathrm{N}^{\mathrm{o}} \cdot 2$

Davenport (2014) Big Data at Work, Harvard Businees School Publising, Boston.

De Castro Cid, B. (2003) Introducción al estudio de los derechos humanos, Editorial Universitas, España, pp. 126-240.

De Miguel Sánchez, N. (2002) Secreto médico, confidencialidad e información sanitaria, Editorial Marcial Pons, Madrid.

De La Torre Díaz, J. et al. (2010) Normas básicas de Bioderecho, Editorial Dykinson, Madrid.

Delgado, G. (1997) Raíces históricas del pensamiento bioético y de la investigación médica en sujetos humanos en Cuba. Bioética. Desde una perspectiva cubana. Editorial Acuario. La Habana.

Delgado Vergara, T. (2017) La enseñanza del Derecho en Cuba, Florida Journal of International Law, Volumen 29. Florida. España.

Diéz Picaso, L. (2008) Sistema de Derechos Fundamentales. Editorial Thomson-Civitas,

Díaz, L. (2006) Derechos Internacional de los Derechos Humanos. Editorial Porrúa. México.

Díaz Rodríguez, S. (2011) Tesis doctoral: Insuficiencias del currículo universitario del profesional del Derecho, sistema de procedimientos metodológicos para la formación del pensamiento iusfilosófico. Universidad de Oriente, Santiago de Cuba.

Díaz Revorio, F. (2009) Los derechos humanos antes los nuevos avances científicos y tecnológicos. Genética e Internet ante la Constitución. Editorial Tirant Lo Blanch. Valencia.

D'Agostino, F. (2002) Bioética y Derecho. Acta Bioethica No 8

Engelhardt, H. (1995) Los fundamentos de la bioética, Editorial Paidos. Barcelona.

Elizari Basterra, F. (1991) Bioética, Editorial San Pablo, España.

Fabelo, J. (1999) ¿Qué tipo de antropocentrismo debe ser erradicado? Cuba Verde. Editorial José Martí. La Habana.

Febles, M. (2013) Un enfoque histórico cultural a la Psicología Ambiental. Editorial Félix Varela. La Habana.

Ferrajoli, L. (2007) Sobre los derechos fundamentales y sus garantías. CNDH México. 
Ferrer Jorge J. y Álvarez, J. (2003) Para fundamentar la Bioética. Editorial UPC. Madrid.

Fernández Bulté, J. (2003) Filosofía del Derecho. Editorial Félix Varela. La Habana.

Funes-Monzote, F. (2009) Transgénicos: ¿Quése gana y qué se pierde? Textos para un debate en Cuba, Editorial Félix Varela, La Habana.

Freyre, E. (1994) El problema de ayudar a morir. Editorial Ciencias Sociales. La Habana.

Freyre, E. (2004) La bioética: enfoque imprescindible. Por una nueva ética. Editorial Félix Varela. La Habana.

Fresno Chávez, C. (2017) La formación de valores: reto del siglo XXI, Editorial Universitaria. La Habana.

Frosini, V. (1997) Derechos humanos y bioética. Editorial Temis. Colombia.

Figueroa, G. (2011) Bioderecho. Enciclopedia de Bioderecho y Bioética, Editorial Comares. España.

Flores, F. (2004) Bioderecho. Editorial Porrúa. México.

Gascón, M. (2008) Bioética, principios, desafíos, debates. Editorial Alianza. España.

García Máynez, E. (1999) Positivismo jurídico, realismo sociológico y iu snaturalismo . Biblioteca de Ética, Filosofía del Derecho y política. México.

García Máynez, E. (1980) Introducción al estudio del Derecho, Editorial Porrúa. Argentina.

García, G. (1995) Hacia una bioética ambiental: una visión prospectiva. El horizonte bioético de las ciencias. Editorial Javeriano. Bogotá.

Garcia Varela, D. (2017) Tesis doctoral: Aspectos constitucionales de la bioética: status jurídico del preembrión. Universidad Complutense de Madrid. España.

Gracia, D. (1989) Fundamentos de bioética. Editorial EUDEMA. Madrid.

Gracia, D. (1996) El Juramento Hipocrático en el desarrollo de la Medicina. Dolentium Hominum. Vol. 31, pp. 22-28.

Gómez, J. (2012) Bioética y ecología: los valores de la naturaleza como norma moral. Editorial Síntesis. España.

Gargantilla, P. (2011) Breve historia de la medicina. Del chamán a la gripe A, Editorial Nowtilus. Madrid.

Gómez-Ullate Rasines, S. (2015) Tesis doctoral: Derechos humanos, Bioética y Derechos de los pacientes. UNED. España.

González Morán, L. (2006) De la Bioética al Bioderecho. Libertad, vida y muerte. Editorial Dykinson. España.

González R. y Arnaiz, G. (2008) Bioética: sabery preocupación. Bioética y Bioderecho. Reflexiones jurídicas ante los retos bioéticos, Editorial Comares. Granada. 
González Morán, L. (2006) De la Bioética al Bioderecho. Libertad, vida y muerte. Editorial Dykinson. Madrid.

Goikoetxea, M. (1999) Introducción a la Bioética. Cuadernos de Teología № 20. Universidad de Deusto. España.

Gordillo, A. (1988) El método en Derecho. Aprender, enseñar, escribir, crear, hacer. Editorial Civitas. Buenos Aires.

Godoy Vázquez, M. O. (2013) Tesis doctoral: Régimen jurídico de la Tecnología reproductiva y la Investigación Biomédica con material humano de origen embrionario: protección de los derechos fundamentales de los sujetos implicados. Universidad Vigo. España. México.

Guastini, R. (2010) Estudios sobre interpretación jurídica. $9^{\text {na }}$ edición, Editorial Porrúa.

Gracia, D. (2007) Fundamentos de bioética. Editorial Triacastela. Madrid.

Gros Espiell, H. (2002) Bioética y Derechos Humanos. Genética Humana en el tercer milenio. Aspectos éticos y jurídicos, Editorial Akal. Madrid.

Gros Espiell, H. (2011) Bioderecho internacional. Enciclopedia de bioderecho y bioética, Editorial Comares. España.

Grisolía, S. (1998) La Biotecnología en el tercer milenio. Biotecnología y Derecho. Perspectivas en Derecho Comparado, Editorial Comares. Granada.

Guerrero Zaplana, J. (2004) El consentimiento informado. Su valoración jurídica en la jurisprudencia, Editorial Lex Nova. Madrid.

Hart, H. (2003) Utilitarismo y derechos naturales. Universidad Externado de Colombia. Bogotá.

Hottois, G. (1991) El paradigma bioético. Una Ética para la Tecnociencia. Editorial Anthropos. Barcelona.

Hottois, G. (2004) ¿Qu'est ce-que la bioéthique? Editore Vrin. Paris.

Horruitinier P. (2009) La universidad cubana: el modelo de formación. Editorial Universitaria. La Habana.

Hegel, W. (1968) Filosofía del Derecho. Editorial Claridad. Buenos Aires.

Hervada, J. (1993) Cuatro lecciones de Derecho natural. Editorial EUNSA. España.

Hervada, J. (2006) Síntesis de historia de la ciencia del Derecho natural. Editorial EUNSA. España.

Martín Mateo, M. (1997) Bioética y Derecho, Editorial Ariel. Barcelona. España.

Martín Mateo, R. (1993) El hombre: una especie en peligro, Editorial Campomanes.

Martínez Morán, N. (2003) Biotecnología, Derecho y Dignidad Humana, Editorial Comares. España.

Rev. Campo Juridico, barreiras-BA v.8 n.2, p. 140-174, Julio-Diciembre, 2020. 
Maritain, J. (2001) Los derechos del hombre. Editorial Palabra. España.

Massini, C. (2005) Filosofía del Derecho. Editorial Lexis Nexis. Argentina.

Mazo Álvarez, H. (2014) El bioderecho: La respuesta jurídica a los problemas que plantea la bioética. Revista Producción + Limpia No 9, pp.74-88

Moran González, L. (2006) De la Bioética al Bioderecho. Editorial Dykinson. España.

Morena Parra, V. (2014) Nuevos retos biotecnológicos para los derechos fundamentales. Editorial Comares. España.

Molina Saldarriaga, C. (2012) La enseñanza clínica del Derecho. Presupuestos metodológicos y teóricos para la inclusión de la interdisciplinariedad en la formación jurídica, Revista Ratio Juris Nº.7, Colombia.

Miralles, Á. (2007) Bioética, bioderecho y biojurídica (reflexiones desde la filosofía del derecho). Anuario de Filosofía del Derecho No .24

Mendoza Cárdenas, H. (2011) La reproducción humana asistida: Un análisis desde la perspectiva biojurídica, Editorial Fontamara, México.

Muñoz Machado, S. y et al. (1999) Los animales y el derecho, Editorial Civitas, España.

MES (2017) Documento base para el diseño de los Planes de estudio E. La Habana.

Navarro, R. y Palomino, R. (1994) Las objeciones de conciencia. Tratado de Derecho Eclesiástico. EUNSA. España.

Núñez Jover, J. (2008) Democratización de la ciencia y geopolítica del saber: ¿Quién decide? ¿Quién se beneficia? Reflexiones sobre Ciencia, Tecnología y Sociedad. Lecturas escogidas. Editorial Ciencias Médicas. La Habana.

Kaufmann, A. (1999) Filosofía del Derecho. Universidad Externado de Colombia.

Kelsen, H. (1994) Teoría pura del Derecho, Editorial Porrúa. México.

Kelsen, H. (1979) Teoría general del Derecho y del Estado. UNAM. México.

Kelsen, H. (1992) ¿Qué es la justicia? Editorial Ariel. Barcelona.

Kottow, M. (1995) Introducción a la Bioética. Editorial Universitaria. Chile.

Kuhn, T. (1998) La Estructura de las Revoluciones Científicas. Fondo de Cultura Económica. México.

Lazo, P. (2011) Formación jurídica, competencias y métodos de enseñanza: premisas . Revista Ius et Praxis $N^{\circ} 1$, Chile, pp. 249-262

Lucas Lucas, R. (2006) Bioética para todos, $3^{\text {a }}$ edición, Editorial Trillas. México. España.

Ollero, A. (2006) Bioderecho. Entre la vida y la muerte, Editorial Thomson Aranzadi.

Rev. Campo Juridico, barreiras-BA v.8 n.2, p. 140-174, Julio-Diciembre, 2020. 
Olano, H. (s.f) La biojurídica: suma de la bioética y de la acción de tutela. Revista Jurídica Piélagus Universidad Surcolombiana, pp.77-87

O.N.U. (1948) Declaración Universal de los Derechos Humanos. Adoptada y proclamada por la Asamblea General en su resolución 217 A (III), de 10 de diciembre de 1948

ONU (1966) Pacto Internacional de Derechos Civiles y Políticos. Adoptado y abierto a la firma, ratificación y adhesión por la Asamblea General en su resolución 2200 A (XXI), de 16 de diciembre de 1966.

ONU (1966) Pacto Internacional de Derechos Económicos, Sociales y Culturales. Adoptado y abierto a la firma, ratificación y adhesión por la Asamblea General en su resolución 2200 A (XXI), de 16 de diciembre de 1966

ONU (1997) Declaración Universal sobre el Genoma Humano y los Derechos Humanos. Adoptada por la conferencia general de la UNESCO el 11 de noviembre de 1997

ONU (2001) Convención internacional contra la clonación de seres humanos con fines de reproducción. Resolución (A/RES/56/93) aprobada por la Asamblea General [sobre la base del informe de la Sexta Comisión (A/56/599)

ONU (2003) Declaración Universal sobre las Datos Genéticos Humanos. Adoptada por la conferencia general de la UNESCO en octubre 16 de 2003

ONU (2005) Declaración Universal sobre Bioética y Derechos Humanos. Adoptada por la conferencia general de la UNESCO el 19 de octubre de 2011.

ONU (2005) Declaración de las Naciones Unidas sobre la Clonación Humana. Aprobada por la Asamblea General el 8 de marzo de 2005 sobre la base del informe de la Sexta Comisión (A/59/516/Add.1)]

Wulfsohn, E. y Gómez Pérez, C. (2002) Bioética y experimentación con animales. Bioética: entre utopías y desarraigos, Editorial Ad Hoc, España.

Rodríguez, M. (2011) Bioética y derechos emergentes. Editorial Dykinson. España.

Romeo Casabona, C. (2011) Bioderecho y bioética. Enciclopedia de bioderecho y bioética. Editorial Comares. España.

Romeo Casabona, C. (2006) Hacia una bioética universal, Cátedra Interuniversitaria de Derecho y Genoma Humano. Bilbao. Granada.

Romeo Casabona, C. et al. (1998) Derecho biomédico y bioética. Editorial Comares.

Romeo Casabona, C. (1994) El Derecho y la Bioética ante los límites de la vida humana. Editorial Centro de Estudios Ramón Areces. Madrid.

Romeo Casabona, C. et al. (2002) Los xenotrasplantes. Aspectos científicos, éticos y jurídicos, Editorial Comares, Granada.

Recasens, L. (1975) Tratado general de filosofía del derecho. Editorial Porrúa. México. Torino.

Rescigno, F. (2005) I diritti degli animali. Da res a soggetti, Editore Giappichelli,

Rev. Campo Juridico, barreiras-BA v.8 n.2, p. 140-174, Julio-Diciembre, 2020. 
Rey Santos O. \& Cruz Sardiñas, T. et al. (2017) La Ley del Medio Ambiente: 20 años después, Editorial UNIJURIS. La Habana.

Pablo IV (2001) Carta Encíclica, Humanae Vitae. Sobre la transmisión de la vida humana. $1^{\text {ra }}$ edición, Editorial San Benito. Italia.

Pardo, A. (1997) Algunas cuestiones en torno a la fundamentación de la bioética. Manual de Bioética General. Editorial Rialp. Madrid.

Pardo, A. (2010) Cuestiones básicas de bioética. Editorial Rialp. España.

Pérez Luño, A. (1995) Derechos Humanos, estado de derecho y constitución. Editorial Tecnos. Madrid.

Pérez Macías, I. (2002) La enseñanza del Derecho en Cuba (1959-2002). Apuntes y Reflexiones, Cuadernos del Instituto Antonio de Nebrija No 5, Universidad Carlos III de Madrid. España.

Polaino-Lorente, A. (1997) Manual de Bioética General. Editorial Rialp. Madrid.

Porras Del Corral, M. (2002) Bioética y Bioderecho. Bioética un dialogo plural. Editorial Universidad Pontificia de Comillas. España.

Potter, V. (1971) Bioethics: Bridge to the future. Edition Prentice-Hall. EUA.

Potter, V. (1998) Bioética puente, bioética global y bioética profunda. Cuadernos de1 Programa Regional de Bioética No 7, pp.20-35.

Potter, V. (2002) Temas bioéticos para el siglo XXI. Revista Latinoamericana de Bioética $\mathrm{N}^{\circ} 2$, pp.150-158.

Post, S. (2004) Introduction. Encyclopedia of Bioethics. $3^{\text {rd }}$ Edition. Macmillan Reference USA e-book. New York

Picasso, E. y Escobar, A. (2010) Principales corrientes filosóficas en bioética. Secretaria de Salud del Distrito Federal. México.

PNUMA (2013) El constitucionalismo en América Latina con la práctica democrática y la participación ciudadana, $\mathrm{ONU}$.

Plan de Estudio A especialidad de Derecho (1976) MES. La Habana, Cuba.

Plan de Estudio B especialidad de Derecho (1980) MES. La Habana, Cuba.

Plan de Estudio C especialidad de Derecho (1986) MES. La Habana, Cuba.

Plan de Estudio C perfeccionado especialidad de Derecho (1998) MES. La Habana, Cuba.

Plan de Estudio D especialidad de Derecho (2008) MES. La Habana, Cuba.

Plan de Estudio E especialidad de Derecho (2017) MES. La Habana, Cuba.

Reich, W. (1978) Encyclopedia of bioethics. Editorial Free Press. EUA. 
Real Academia de la Lengua (2015) Diccionario de la lengua española. Disponible en: http://lema.rae.es/drae/?val=bioeticaReal

Singer, P. (1997) Repensar la vida y la muerte. El derrumbe de nuestra ética tradicional . Editorial Paidos. Barcelona.

Schaefer Rivabem, F. (2017) Bioderecho: ¿una disciplina autónoma? Revista Bioética o 25, pp.282-289 España.

Serrano Ruiz-Calderón, J. (2002) Nuevas cuestiones de bioética. Editorial EUNSA.

Serrano Ruiz-Calderón, J. (2005) Retos jurídicos de la Bioética. Editorial Internacionales Universitarias. España.

Serrano Ruiz-Calderón, J. (2001) Bioética y Derecho. Manual de Bioética. Editorial Ariel. España.

Sgreccia, E. (2007) Manual de Bioética: Fundamentos y ética biomédica. Biblioteca de Autores Cristianos. España.

Oswald, U. (2002) El reordenamiento de la naturaleza: Impactos ambientales y sociales de los transgénicos. La vida en venta: transgénicos, Patentes y Biodiversidad. Editorial Bôll. España.

Tarasco, M. (2000) Bioética: Tendencias y corrientes filosóficas. Introducción a la Bioética, Editorial Méndez. México.

Tascón, M. (2013) Big Data: Pasado, presente y futuro, Editorial Telos. España.

Tamayo Pineda, N. (2012) Glosario de Términos Jurídicos, Editorial ONBC. La Habana.

Tealdi, J. (2008) Diccionario Latinoamericano de Bioética. UNESCO - Red Latinoamericana y del Caribe de Bioética: Universidad Nacional de Colombia.

Torres, R. (2001) Glosario de bioética. Editorial Acuario. La Habana. Habana.

Tejeda del Prado, L. (1999) Identidad y crecimiento humano. Editorial Gente Nueva. La

Truyol y Serra, A. (2000) Los Derechos Humanos. Editorial Tecnos. España.

Junquera De Estéfani, R. (2012) Derecho, Bioética y Bioderecho, un cruce de caminos para un derecho emergente: el derecho a ser informado en la asistencia biomédica. Dilemas bioéticos actuales: Investigación biomédica, principio y final de la vida, Editorial Dykinson. Madrid.

Valdés, E. (2018) ¿Qué es el bioderecho? Propuesta metodológica y doctrinaria para resolver problemas jurídicos de última generación. Estudios acerca del derecho de la salud II. Editorial Thomson Reuters-La Ley. Argentina.

Valdés, E. (2015) Bioderecho, daño genético y derechos humanos de cuarta generación, Boletín Mexicano de Derecho Comparado No. 144 
Valdés, E. (2015) Bioderecho y sujeto de derechos. Recategorización jurídica de la manipulación genética no terapéutica en estado embrionario preimplantacional y del concep to de existencia legal de la persona, Derecho y Genoma Humano $\mathrm{N}^{\circ} .43$

Vásquez, R. (2012) Bioética y derecho. Fundamentos y problemas actuales. Editorial Fontamara. México.

Vila Coro, M. (2005) El Marco Jurídico en la Bioética. Cuadernos de Bioética No .58

Vila Coro, $\mathrm{M}^{\mathrm{a}}$ (2007) La bioética en la encrucijada: Sexualidad, aborto y eutanasia . Editorial Dykinson. España. España.

Vila, M. (1995) Introducción a la biojurídica. Universidad Complutense de Madrid.

Villán, C. (2002) Curso de derecho internacional de los Derechos humanos. Editorial Trota. Madrid.

Villalain Blanco, J. (2001) El origen de la Bioética y su Desarrollo, Editorial Ariel. España.

Villavella Armengol, C. (2011) Los derechos humanos y el medio ambiente su tratamiento en el Derecho Constitucional comparado, Revista de estudios jurídicos CUBALEX. La Habana.

Vives-Rego, J. (2010) Los dilemas medioambientales del Siglo XXI ante la ecoética. Editorial Bubok. Barcelona.

Velarde, C. (2004) Universalismo de derechos humanos, Editorial Civitas. Madrid.

Velásquez, J. (2011) El necesario rescate de los conceptos naturaleza y naturaleza humana de cara a los retos de la reflexión en la bioética y el bioderecho. Revista Facultad de derecho y ciencias políticas $\mathrm{N}^{\circ}$ 41, pp. 401-426.

Zarate Cuello, A. (2014) Tesis doctoral Derecho: El Bioderecho como instrumento en la determinación de los límites a la libertad de investigación. Especial referencia a la eu genesia positiva en genética humana. Universidad Complutense de Madrid. España. 